\title{
Simple monetary policy rules and exchange rate uncertainty
}

\author{
Kai Leitemo Ulf Söderström*
}

First draft: October 2000

This version: June 2001

\begin{abstract}
We analyze the performance and robustness of some common simple rules for monetary policy in a New-Keynesian open economy model under different assumptions about the exchange rate model. Adding the exchange rate to an optimized Taylor rule gives only small improvements in terms of economic stability in most model configurations. The Taylor rule is also slightly more robust to uncertainty about the exchange rate model than are rules that respond to the rate of exchange rate depreciation. Our results thus indicate that the Taylor rule may be sufficient to stabilize a small open economy, also under exchange rate model uncertainty.
\end{abstract}

Keywords: Open economy; Exchange rate determination; Model uncertainty; Robustness of policy rules

JEL Classification: E52, E58, F41

*Leitemo: Research Department, Norges Bank, P.O. Box 1179, 0107 Oslo, Norway; kai.leitemo@norges-bank.no. Söderström: Research Department, Sveriges Riksbank, SE-103 37 Stockholm, Sweden; ulf.soderstrom@riksbank.se. We are grateful to Malin Adolfson, Pierpaolo Benigno, Paul De Grauwe, Richard Dennis, Hans Dillén, Jean-Paul Lam, Guy Meredith, Marianne Nessén, Athanasios Orphanides, Stefan Palmqvist, Øistein Røisland, Andy Rose, Glenn Rudebusch and Anders Vredin for helpful comments. We also thank seminar participants at Sveriges Riksbank, the Norwegian School of Economics and Business Administration, the Norges Bank workshop on "The conduct of monetary policy in open economies" in October 2000, and the FRBSF/SIEPR conference on "Asset Prices, Exchange Rates, and Monetary Policy" in March 2001. Ulf Söderström gratefully acknowledges financial support from the Jan Wallander and Tom Hedelius foundation. The views expressed in this paper are solely the responsibility of the authors, and should not be interpreted as reflecting the views of Norges Bank or Sveriges Riksbank. 


\section{Introduction}

In open economies, the exchange rate is an important element in the transmission of monetary policy. In addition to the standard aggregate demand and expectations channels in closed economies, the exchange rate introduces a number of new channels in the monetary transmission mechanism (see also Svensson, 2000): (i) the real exchange rate affects the relative price between domestic and foreign goods, and thus contributes to the aggregate demand channel; $(i i)$ the exchange rate affects consumer prices directly via the domestic currency price of imports; and (iii) the exchange rate affects the price of imported intermediate goods, and thus the pricing decisions of domestic firms. It would therefore seem natural to include the exchange rate as an indicator for monetary policy in an open economy. The recent years have also seen a surge in research concerning monetary policy in open economies. ${ }^{1}$

However, movements in the exchange rate are not very well understood in practice. In particular, the parity conditions typically used in theoretical analysesuncovered interest rate parity (UIP) and purchasing power parity (PPP) - do not find much support in empirical studies. ${ }^{2}$ Furthermore, the equilibrium real exchange rate is not easily observed by central banks. Given the high degree of uncertainty regarding exchange rate determination, a challenge for monetary policymakers in open economies is to design policy strategies that are reasonably robust to alternative specifications of the exchange rate model. ${ }^{3}$

The main objective of this paper, therefore, is to study the role of the exchange rate as an indicator for monetary policy when there is uncertainty about the exchange rate model. The analysis is performed in three steps: we first analyze a "baseline model" to see whether extending an optimized Taylor (1993) rule to include a measure of the exchange rate leads to any improvement in terms of a standard intertemporal loss function for the central bank. Second, we perform the same analysis in a variety of model configurations, to see how sensitive the results are to the exact specification of the model. Third, we examine the robustness of the different policy rules to model uncertainty by analyzing the outcome when using the optimized policy rules from the baseline model in the alternative model specifications.

\footnotetext{
${ }^{1}$ A non-exhaustive list includes Ball (1999), Svensson (2000), Taylor (1999), McCallum and Nelson (1999), Obstfeld and Rogoff (2000), Leitemo (2000b), Batini et al. (2001), Dennis (2000), Benigno and Benigno (2000), Corsetti and Pesenti (2000), Monacelli (1999) and Ghironi (1999).

${ }^{2}$ See, e.g., the survey by Froot and Thaler (1990). On the other hand, McCallum (1994), Chinn and Meredith (2000) and others argue that the empirical rejection of UIP is due to a failure to properly account for other relationships in the economy, such as the behavior of monetary policy.

${ }^{3}$ See McCallum $(1988,1999)$ on the robustness of policy rules.
} 
The analysis is performed in a New-Keynesian model of a small open economy, incorporating inertia and forward-looking behavior in the determination of both output and inflation. Our framework allows for several modifications of the model determining the exchange rate and its influence on the domestic economy. These modifications are introduced in three broad categories. First, we allow for longerterm departures from PPP than what is due to nominal rigidities by considering varying degrees of exchange rate pass-through onto import prices and thus to CPI inflation. The departure from PPP is motivated by the overwhelming evidence of pricing-to-market and incomplete exchange rate pass-through. ${ }^{4}$

Second, we study different departures from the rational expectations UIP condition, in the form of non-rational exchange rate expectations and varying behavior of the risk premium on foreign exchange. The first departure from rational expectations UIP is also motivated by empirical evidence. Although most evidence from surveys of expectations in the foreign exchange market point to expectations not being completely rational (e.g., Frankel and Froot, 1987), rational expectations remain the workhorse assumption about expectation formation in structural and theoretical policy models. We extend such analyses by considering exchange rate expectations being partially adaptive. The second departure from UIP considers the behavior of the foreign exchange risk premium, by allowing for varying degrees of risk premium persistence.

Third, we analyze the consequences of uncertainty concerning the equilibrium real exchange rate. Measuring the equilibrium real exchange rate is a difficult task for policymakers, similar to measuring the equilibrium real interest rate or the natural level of output. For this reason, rules that respond to the deviation of the real exchange rate from its equilibrium (or steady-state) level may not be very useful in practice. In some versions of the model, we try to capture such uncertainty by letting the central bank respond to a noisy measure of the real exchange rate.

Our results indicate that the gains from extending an optimized Taylor rule to include a measure of the exchange rate (the nominal or real rate of depreciation or the level of the real exchange rate) are small in most specifications of the model. Furthermore, the outcome from an optimized Taylor rule is often very close to the outcome of the unrestricted optimal policy rule under commitment. Policy rules that respond to the rate of exchange rate depreciation are slightly more sensitive than the Taylor rule to model uncertainty, in particular with respect to the formation of

\footnotetext{
${ }^{4}$ See, e.g., Naug and Nymoen (1996) or Alexius and Vredin (1999) for empirical evidence, or Goldberg and Knetter (1997) for a survey.
} 
exchange rate expectations. Thus, in our model the output gap and annual CPI inflation seem sufficient as indicators for monetary policy in the open economy, also under uncertainty about the exchange rate.

The remainder of the paper is outlined as follows. The next section presents the model framework and discusses the monetary transmission mechanism as well as the policy rules and objectives of the monetary authorities. Section 3 briefly discusses our methodology and the calibration of the model. Section 4 analyzes the performance of policy rules in different specifications of the model and the robustness of policy rules to model uncertainty. Finally, Section 5 contains some concluding remarks.

\section{A model of a small open economy}

The model we use is a small-scale open economy model in the New-Keynesian tradition, similar to those of Batini and Haldane (1999), Svensson (2000), Batini and Nelson (2001) and Leitemo (2000a). ${ }^{5}$ The model is quarterly, all variables are measured as (log) deviations from long-run averages, and interest rates are measured as annualized rates while inflation rates are measured on a quarterly basis.

Monetary policy in the model affects the economy through several transmission channels. First, due to nominal rigidities, the central bank can influence the real interest rate by setting the nominal rate. Monetary policy works through this "interest rate channel" by changing consumption demand through the familiar intertemporal substitution effect. Second, monetary policy influences the price of domestic goods in terms of foreign goods via the price of domestic currency. The exchange rate affects the open economy in different ways, making it convenient to distinguish between a direct channel and an indirect channel. The "direct exchange rate channel" affects the price of imported goods in terms of domestic currency, which directly influences the consumer price level. The "indirect exchange rate channel" influences aggregate demand through the price of domestic goods in terms of foreign goods, and domestic pricing decisions through the price of imported inputs.

\footnotetext{
${ }^{5}$ Microfoundations for this class of open economy models are provided by, e.g., Svensson (2000) and Benigno and Benigno (2000).
} 


\subsection{Output and inflation}

Aggregate output is demand-determined (in a world of monopolistic competition), and is partially forward-looking. ${ }^{6}$ Aggregate demand is influenced by the real interest rate through intertemporal substitution effects, and by the real exchange rate through intratemporal price effects. Output is assumed to be predetermined one period (cf. Svensson and Woodford, 1999), and there are explicit lags in the monetary transmission mechanism. Thus, the output gap (the log deviation of output from its natural level) is given by

$$
y_{t+1}=\beta_{y}\left[\varphi_{y} y_{t+2 \mid t}+\left(1-\varphi_{y}\right) y_{t}\right]-\beta_{r}\left(i_{t}-4 \pi_{t+1 \mid t}^{d}\right)+\beta_{q} q_{t}+\beta_{y f} y_{t}^{f}+\varepsilon_{t+1}^{y},
$$

where $\beta_{y} \leq 1 ; i_{t}$ is the (annualized) quarterly interest rate, set by the central bank; $\pi_{t}^{d} \equiv p_{t}^{d}-p_{t-1}^{d}$ is the quarterly rate of domestic inflation; $q_{t}$ is the real exchange rate; $y_{t}^{f}$ is the foreign output gap; and $0 \leq \varphi_{y} \leq 1$ measures the degree of forwardlooking behavior in agents' consumption decisions. ${ }^{7}$ Throughout, the notation $x_{t+1 \mid t}$ denotes $\mathrm{E}_{t} x_{t+1}$, i.e., the rational expectation of the variable $x$ in period $t+1$, given information available in period $t$. The variable $i_{t}-4 \pi_{t+1 \mid t}^{d}$ is thus the quarterly exante real interest rate, in annualized terms. Finally, the disturbance $\varepsilon_{t+1}^{y}$ is a white noise shock with variance $\sigma_{y}^{2}$.

Domestic inflation follows an expectations-augmented Phillips curve, and so is influenced by the tightness in product and factor markets via aggregate output and the real exchange rate, and is also assumed to be predetermined one period: ${ }^{8}$

$$
\pi_{t+1}^{d}=\varphi_{\pi} \pi_{t+2 \mid t}^{d}+\left(1-\varphi_{\pi}\right) \pi_{t}^{d}+\gamma_{y} y_{t+1 \mid t}+\gamma_{q} q_{t+1 \mid t}+\varepsilon_{t+1}^{\pi}
$$

where $0 \leq \varphi_{\pi} \leq 1$ measures the degree of forward-looking behavior in pricing and wage setting. Again, the disturbance $\varepsilon_{t+1}^{\pi}$ is white noise with variance $\sigma_{\pi}^{2}$.

Although in most versions of the model the pass-through of exchange rate movements to import prices is instantaneous, some versions will allow for slow exchange

\footnotetext{
${ }^{6}$ Inertia in aggregate demand could come from, e.g., habit formation (Estrella and Fuhrer, 1998; Fuhrer, 2000), costs of adjustment (Pesaran, 1987; Kennan, 1979; Sargent, 1978), or rule-of-thumb behavior (Amato and Laubach, 2000).

${ }^{7}$ With $\varphi_{y}=0$ and $\beta_{y}<0$, the formulation in (1) allows for a purely backward-looking output gap with a coefficient on lagged output below unity as in, e.g., Rudebusch (2000a) or Batini and Haldane (1999).

${ }^{8}$ This is similar to the open-economy Phillips curve specification of Walsh (1999) but with inertia, and can thus be seen as an open-economy application of the wage contracting model of Buiter and Jewitt (1981) and Fuhrer and Moore (1995), along the lines of Batini and Haldane (1999). See also footnote 6 .
} 
rate pass-through. Thus import prices adjust to movements in foreign prices according to the simple error correction mechanism

$$
\begin{aligned}
p_{t}^{M} & =p_{t-1}^{M}+\kappa\left(p_{t}^{f}+s_{t}-p_{t-1}^{M}\right) \\
& =(1-\kappa) p_{t-1}^{M}+\kappa\left(p_{t}^{f}+s_{t}\right),
\end{aligned}
$$

where $\kappa \leq 1, p_{t}^{f}$ is the foreign price level, and $s_{t}$ is the nominal exchange rate. ${ }^{9}$ Imported inflation then follows

$$
\pi_{t}^{M}=(1-\kappa) \pi_{t-1}^{M}+\kappa\left(\pi_{t}^{f}+\Delta s_{t}\right)
$$

and aggregate CPI inflation is given by

$$
\pi_{t}=(1-\eta) \pi_{t}^{d}+\eta \pi_{t}^{M}
$$

where $0<\eta<1$ is the weight of imported goods in aggregate consumption.

Foreign output and inflation are assumed to follow the stationary autoregressive processes

$$
\begin{aligned}
& y_{t+1}^{f}=\rho_{y f} y_{t}^{f}+\varepsilon_{t+1}^{y f}, \\
& \pi_{t+1}^{f}=\rho_{\pi f} \pi_{t}^{f}+\varepsilon_{t+1}^{\pi f},
\end{aligned}
$$

where $0 \leq \rho_{y f}, \rho_{\pi f}<1$, and the shocks $\varepsilon_{t+1}^{y f}, \varepsilon_{t+1}^{\pi f}$ are white noise with variances $\sigma_{y f}^{2}, \sigma_{\pi f}^{2}$. The foreign nominal interest rate follows the simple Taylor-type rule

$$
i_{t}^{f}=g_{\pi f} \bar{\pi}_{t}^{f}+g_{y f} y_{t}^{f}
$$

where $\bar{\pi}_{t}^{f}=\sum_{\tau=0}^{3} \pi_{t-\tau}^{f}$ is the annual foreign inflation rate.

\subsection{Exchange rate determination}

The model uncertainty that is the focus of the paper is primarily related to the determination of the exchange rate. As mentioned in the Introduction, many empirical studies have failed to find support for uncovered interest rate parity, and several explanations for these failures have been suggested, such as persistent movements in the exchange rate risk premium or non-rational exchange rate expectations. In order to allow for different deviations from UIP, the nominal exchange rate (the price of

\footnotetext{
${ }^{9} \mathrm{~A}$ value of $\kappa=1$ represents instantaneous pass-through, and $\kappa=0$ no pass-through. See Adolfson (2000) for a more detailed analysis of incomplete pass-through in a similar model, and, e.g., Naug and Nymoen (1996) for some empirical evidence.
} 
foreign currency in terms of domestic currency) is assumed to satisfy the modified interest rate parity condition

$$
s_{t}=\hat{s}_{t+1, t}+\frac{1}{4}\left[i_{t}^{f}-i_{t}\right]+u_{t}^{s},
$$

where $\hat{s}_{t+1, t}$ is the possibly non-rational expectation of the exchange rate in period $t+1$, given information in period $t$, and $u_{t}^{s}$ is a risk premium, which follows the stationary process

$$
u_{t+1}^{s}=\rho_{s} u_{t}^{s}+\varepsilon_{t+1}^{s},
$$

where $0 \leq \rho_{s}<1$ and $\varepsilon_{t+1}^{s}$ is white noise with variance $\sigma_{s}^{2}$. To analyze the effects of persistent movements in the risk premium, we will vary the persistence parameter $\rho_{s}$, holding the variance $\sigma_{s}^{2}$ fixed.

Several studies reject the hypothesis that exchange rate expectations are rational, e.g., MacDonald (1990), Cavaglia et al. (1993), Ito (1990) and Froot and Frankel (1989). ${ }^{10}$ Using survey data, Frankel and Froot (1987) test the validity of alternative expectation formation mechanisms on the foreign exchange market: adaptive expectations, equilibrium (or regressive) expectations, and distributed-lag expectations. Their results indicate that expectations at the 3-month, 6-month and 12-month horizon can be explained by any of the three models. Since these three expectations formation mechanisms have very similar consequences in our model (they all make the exchange rate process more backward-looking), we here concentrate on adaptive expectations as an alternative to rational expectations. ${ }^{11}$ Thus, the expected exchange rate in equation (9) is given by a combination of rational and adaptive expectations according to

$$
\hat{s}_{t+1, t}=\vartheta s_{t+1 \mid t}+(1-\vartheta) s_{t+1, t}^{A},
$$

where $s_{t+1 \mid t}$ represents rational expectations, $s_{t+1, t}^{A}$ represents adaptive expectations, and the parameter $\vartheta$ measures the degree of rationality.

Under adaptive expectations, agents update their exchange rate expectations slowly in the direction of the observed exchange rate, so their expectations are given by

$$
s_{t+1, t}^{A}=(1-\xi) s_{t}+\xi s_{t, t-1}^{A},
$$

\footnotetext{
${ }^{10}$ On the other hand, Liu and Maddala (1992) and Osterberg (2000), using cointegration techniques, cannot reject the hypothesis that expectations are rational.

${ }^{11}$ Results when using equilibrium/regressive expectations or distributed-lag expectations are available from the authors upon request.
} 
where $0<\xi<1$ measures the rate of updating. The expected exchange rate is then a weighted average of previously observed exchange rates:

$$
s_{t+1, t}^{A}=(1-\xi) \sum_{\tau=0}^{t} \xi^{\tau} s_{t-\tau}
$$

Thus, as the weight on rational expectations approaches zero, exchange rate expectations become predominantly backward-looking.

The real exchange rate is defined in terms of domestic prices as

$$
q_{t}=s_{t}+p_{t}^{f}-p_{t}^{d}
$$

However, instead of directly observing the real exchange rate's deviation from its equilibrium value, in some versions of the model we assume that the central bank can only observe the noisy variable

$$
\hat{q}_{t}=q_{t}+u_{t}^{q}
$$

where the measurement error $u_{t}^{q}$ follows the stationary $\operatorname{AR}(1)$ process

$$
u_{t+1}^{q}=\rho_{q} u_{t}^{q}+\varepsilon_{t+1}^{q},
$$

where $0 \leq \rho_{q}<1$ and the shock $\varepsilon_{t}^{q}$ is white noise with variance $\sigma_{q}^{2}$. This specification is intended to capture the uncertainty involved in measuring the equilibrium real exchange rate, uncertainty that poses difficult problems for policymakers who want to respond to the real exchange rate's deviation from equilibrium. ${ }^{12}$

\subsection{Monetary policy rules}

Monetary policy is conducted by a central bank which follows a simple Taylor-type rule when setting its interest rate, under perfect commitment. Thus, the central bank sets the interest rate as a linear function of the deviations of the current output gap and the annual CPI inflation rate (and possibly an exchange rate variable) from their zero targets. ${ }^{13}$

As a benchmark we use the standard Taylor (1993) rule (denoted "T"), where the interest rate depends only on output and inflation;

$$
T: \quad i_{t}=f_{\pi} \bar{\pi}_{t}+f_{y} y_{t},
$$

\footnotetext{
${ }^{12}$ This way of modeling data uncertainty is similar to that used by Orphanides (1998) and Rudebusch (2000b) when analyzing the effects of output gap uncertainty.

${ }^{13}$ These policy are not reaction functions in the strict sense, since they include the exchange rate variables (either directly or indirectly via CPI inflation), which are not predetermined.
} 
where $\bar{\pi}_{t}=\sum_{\tau=0}^{3} \pi_{t-\tau}$ is the four-quarter CPI inflation rate. The coefficients of this policy rule are chosen by the central bank to minimize a standard intertemporal loss function defined below. ${ }^{14}$

We then analyze three types of exchange rate rules, where the optimized Taylor rule is extended to include an exchange rate variable. The first rule (denoted " $\Delta S$ ") includes the change in the nominal exchange rate, ${ }^{15}$

$$
\Delta S: \quad i_{t}=f_{\pi} \bar{\pi}_{t}+f_{y} y_{t}+f_{\Delta s} \Delta s_{t}
$$

the second rule (denoted " $Q$ ") includes the level of the real exchange rate (possibly observed with an error),

$$
Q: \quad i_{t}=f_{\pi} \bar{\pi}_{t}+f_{y} y_{t}+f_{q} \hat{q}_{t}
$$

and the third rule (denoted " $\Delta Q$ ") includes the change in the real exchange rate,

$$
\Delta Q: \quad i_{t}=f_{\pi} \bar{\pi}_{t}+f_{y} y_{t}+f_{\Delta q} \Delta \hat{q}_{t}
$$

In these three exchange rate rules, the optimized coefficients from the Taylor rule (17) are taken as given, and the coefficient on the respective exchange rate variable is optimized. Thus, the value of the exchange rate coefficient indicates whether there are any extra gains from adding the exchange rate variable to the optimized Taylor rule. ${ }^{16}$ It should however be kept in mind that the coefficients on the exchange rate variables do not represent the full response to movements in the exchange rate: in an open economy, also the Taylor rule (17) responds to movements in the exchange rate, since these movements affect CPI inflation. ${ }^{17}$

\footnotetext{
${ }^{14}$ We do not include a lagged interest rate in the policy rules: when optimizing the Taylor rule, the coefficient on the lagged interest rate is typically small. See more below.

${ }^{15}$ Our numerical algorithm is not very reliable when including non-stationary state variables, such as the level of the nominal exchange rate. We therefore confine the analysis to policy rules including stationary variables.

${ }^{16}$ If we optimize all coefficients in the exchange rate rules, the results are virtually identical, and all conclusions remain unaltered.

${ }^{17}$ Using the domestic inflation rate in the Taylor rules instead of CPI inflation would result in a rule more closely related to a closed-economy Taylor rule. However, the original rule proposed by Taylor (1993) is formulated in terms of CPI inflation, and most central banks include imported inflation in their official target rates of inflation. Therefore we choose to use the CPI inflation rate in the policy rules.
} 


\subsection{Central bank preferences}

The policy rules will be evaluated using the intertemporal loss function

$$
\mathrm{E}_{t} \sum_{\tau=0}^{\infty} \delta^{\tau} L_{t+\tau}
$$

where the period loss function is of the standard quadratic form

$$
L_{t}=\bar{\pi}_{t}^{2}+\lambda y_{t}^{2}+\nu\left(i_{t}-i_{t-1}\right)^{2}
$$

and $0<\delta<1$ is the central bank's discount factor. The parameters $\lambda$ and $\nu$ measure the weights on stabilizing output and interest rate movements relative to stabilizing inflation.

It can be shown (see Rudebusch and Svensson, 1999) that as the discount factor $\delta$ approaches unity, the value of the intertemporal loss function (21) becomes proportional to the unconditional expected value of the period loss function (22), i.e.,

$$
\mathrm{E} L_{t}=\operatorname{Var}\left(\bar{\pi}_{t}\right)+\lambda \operatorname{Var}\left(y_{t}\right)+\nu \operatorname{Var}\left(\Delta i_{t}\right)
$$

Thus, for each policy rule we calculate the unconditional variances of the goal variables $\left(\bar{\pi}_{t}, y_{t}, \Delta i_{t}\right)$, in order to evaluate the weighted variances in (23). For comparison, we normalize the value of the loss function in each model with the value resulting from the unrestricted optimal outcome, when the central bank optimizes its objective function under precommitment. This will give an idea of the quantitative differences in welfare resulting from the different policy rules.

To solve the model, we rewrite it on state-space form as

$$
\left[\begin{array}{c}
x_{1 t+1} \\
\mathrm{E}_{t} x_{2 t+1}
\end{array}\right]=A\left[\begin{array}{c}
x_{1 t} \\
x_{2 t}
\end{array}\right]+B i_{t}+\varepsilon_{t+1},
$$

where $x_{1 t}$ is a vector of predetermined state variables, $x_{2 t}$ is a vector of forwardlooking variables, and $\varepsilon_{t+1}$ is a vector of disturbances to the predetermined variables. The period loss function (22) can then be expressed as

$$
L_{t}=z_{t}^{\prime} K z_{t}
$$

where $K$ is a matrix of preference parameters and $z_{t}$ is a vector of potential goal variables (and other variables of interest) that can be constructed from the state variables and the interest rate as

$$
z_{t}=C_{x} x_{t}+C_{i} i_{t}
$$


Appendix B.1 shows how to set up the system; Appendix B.2 demonstrates how to calculate the dynamics of the system under a given simple policy rule, following Söderlind (1999); and Appendix B.3 shows how to calculate the unconditional variances of state and goal variables under the different rules.

\section{Methodology and calibration}

\subsection{Methodology}

Our primary interest lies in uncertainty about the determination of the exchange rate and its effects on the economy. For these purposes the model has been designed to allow for variations in the exchange rate model in several different dimensions:

1. The degree of exchange rate pass-through to import prices: the parameter $\kappa$ in equation (4);

2. The persistence of the risk premium: the parameter $\rho_{s}$ in equation (10);

3. The volatility of the real exchange rate measurement error: the variance of $\varepsilon_{t}^{q}$, $\sigma_{q}^{2}$, in equation (16); and

4. The degree of rationality in exchange rate expectations: the parameter $\vartheta$ in equation (11).

In a purely backward-looking model, it would be fairly straightforward to define the stochastic properties of the uncertain parameters and explicitly solve for the optimal policy rule under model uncertainty. ${ }^{18}$ However, when the model contains forward-looking elements, such an approach is not possible, so we must use an alternative approach when investigating the effects of model uncertainty. First, after analyzing a baseline specification of the model, we vary the parameters in consideration and analyze how the policy rules and the outcomes differ across parameter configurations. Second, we assume that the central bank is ignorant about the true behavior of the exchange rate and optimizes its policy rule under the baseline configuration of parameters, and we analyze the outcome when the actual configuration turns out to be different. The first exercise will indicate how the different rules perform under varying assumptions about the economy, while the second exercisealong the lines of Rudebusch (2000a) - will give an indication as to what types of

\footnotetext{
${ }^{18}$ See, e.g., Söderström (2000a,b) or Sack (2000) for such analyses of closed economies.
} 
policy rules are more robust to variations in the parameters, and thus more attractive when the true state of the economy is unknown.

Since the model cannot be solved analytically, we will use numerical methods, developed by Backus and Driffill (1986), Currie and Levine (1993) and others, as described by Söderlind (1999).

\subsection{Model calibration and the propagation of shocks}

To calibrate the model, we choose parameter values that we deem reasonable in order to match the dynamic behavior of the model with the stylized facts of small open economies. In the output equation (1) the parameter $\beta_{y}$ on the lagged and future output gap is set to 0.9 , the degree of forward-looking behavior is set to 0.3 , and the elasticities with respect to the real interest rate, the real exchange rate and the foreign output gap are set to $0.15,0.05$ and 0.12 , respectively. In the determination of domestic inflation in equation (2) the degree of forward-looking behavior is slightly higher, at 0.5 , and the elasticities with respect to output and the real exchange rate are set to 0.05 and 0.01 , respectively. The weight of imported goods in the CPI basket is set to 0.35 , which is close to the actual weights in Norway and Sweden.

Foreign output and inflation are both assigned the AR-parameter 0.8, and the foreign central bank's Taylor rule has the traditional coefficients of 0.5 on the output gap and 1.5 on inflation. The domestic central bank's preference parameters are set such that the loss function penalizes squared deviations of inflation from target twice as heavily as squared output deviations (so $\lambda=0.5$ ), and there is some preference for interest rate smoothing $(\nu=0.1)$; and the discount factor $\delta$ is set close to unity, at 0.99 . The variances of the disturbance terms are taken from a structural vector auto-regression (VAR) on the Norwegian economy, so $\sigma_{y}^{2}=0.656, \sigma_{\pi}^{2}=0.389, \sigma_{y f}^{2}=$ 0.083 , and $\sigma_{\pi f}^{2}=0.022$ (see Leitemo and Røisland, 2000, for details). While the persistence parameter of the risk premium will vary between model configurations (see below), the variance of the risk premium shock is always fixed at 0.844 , a value also taken from the VAR-model. Finally, the persistence parameter of the real exchange rate measurement error (when applicable) is set to 0.3 .

Table 1 summarizes these parameter values, which are kept fixed throughout the analysis.

In the baseline model, the parameters relating to the exchange rate are set to their conventional values, so there is instantaneous exchange rate pass-through $(\kappa=1)$, the risk premium is not very persistent $\left(\rho_{s}=0.3\right)$, there is no error when observing 
Table 1: Fixed parameter values

\begin{tabular}{clllllllll}
\hline \hline \multicolumn{2}{c}{ Output } & \multicolumn{2}{c}{ Inflation } & \multicolumn{2}{c}{ Foreign economy } & \multicolumn{2}{c}{ Exchange rate } & \multicolumn{2}{c}{ Preferences } \\
\hline$\beta_{y}$ & 0.9 & $\varphi_{\pi}$ & 0.5 & $\rho_{y f}$ & 0.8 & $\sigma_{s}^{2}$ & 0.844 & $\delta$ & 0.99 \\
$\varphi_{y}$ & 0.3 & $\gamma_{y}$ & 0.05 & $\rho_{\pi f}$ & 0.8 & $\rho_{q}$ & 0.3 & $\lambda$ & 0.5 \\
$\beta_{r}$ & 0.15 & $\gamma_{q}$ & 0.01 & $g_{y f}$ & 0.5 & & & $\nu$ & 0.1 \\
$\beta_{q}$ & 0.05 & $\eta$ & 0.35 & $g_{\pi f}$ & 1.5 & & & & \\
$\beta_{y f}$ & 0.12 & $\sigma_{\pi}^{2}$ & 0.389 & $\sigma_{y f}^{2}$ & 0.083 & & & & \\
$\sigma_{y}^{2}$ & 0.656 & & & $\sigma_{\pi f}^{2}$ & 0.022 & & & \\
\hline
\end{tabular}

Table 2: Alternative model configurations

\begin{tabular}{lccc}
\hline \hline \multicolumn{1}{c}{ Configuration } & Parameter involved & Baseline value & Range of variation \\
\hline 1. Exchange rate pass-through & $\kappa$ & 1 & {$[0.1,1]$} \\
2. Persistence of risk premium & $\rho_{s}$ & 0.3 & {$[0,0.9]$} \\
3. Variance of measurement error & $\sigma_{q}^{2}$ & 0 & {$[0,3]$} \\
4. Adaptive expectations & $\vartheta$ & 1 & {$[0,1]$} \\
& $\xi$ & - & 0.1 \\
\hline
\end{tabular}

the real exchange rate $\left(\sigma_{q}^{2}=0\right)$, and expectations are rational $(\vartheta=1)$. We then analyze each departure from the baseline in turn, varying the rate of exchange rate pass-through, the persistence of the risk premium, the variance of the measurement error, and the weight on rational expectations. Under adaptive expectations, the parameter $\xi$ describing the rate of updating is set to 0.1 , which is slightly larger than the empirical findings of Frankel and Froot (1987). Table 2 presents the values of the exchange rate parameters in the baseline model, and their range of variation in the alternative configurations.

In order to get an overview of the transmission mechanism in the model, it is useful to examine the impulse responses of the baseline model under the optimized Taylor rule (to be presented below), in particular in response to three shocks: an output shock, a domestic inflation shock and a shock to the risk premium. The impulse responses to a one standard deviation shock in each disturbance are shown in Figure 1.

A shock to the output gap in the first row produces a level of output that is above the natural level for four quarters before slightly undershooting the natural level for the following five quarters and then converging towards the equilibrium (zero) level. CPI inflation first falls (reacting to an initial nominal exchange rate appreciation) 
Figure 1: Impulse responses under optimized Taylor rule in baseline model

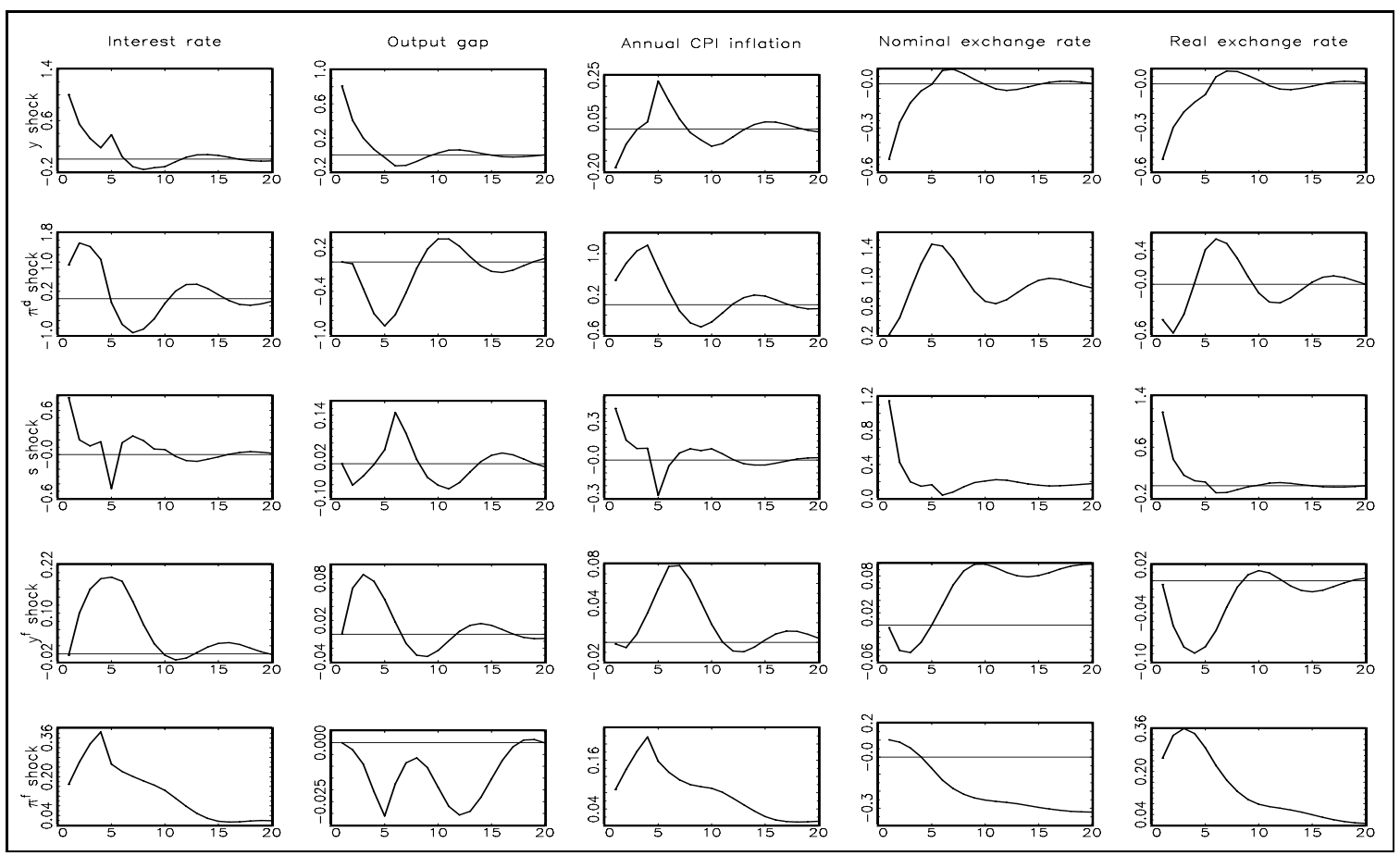

Note: One standard deviation shocks, policy given by rule $T$ in Table 3.

and then increases above the target level (due to the positive output gap). As a result of the output and inflation movements, the nominal interest rate is quickly raised and then returns back to zero. Since the output disturbance has small effects on domestic inflation (not shown), and the long-run effects on the domestic price level are virtually zero, the nominal and real exchange rates follow each other closely, and the nominal exchange rate settles at the same level as before the shock. (The long-run value of the nominal exchange rate is given by the differential between the domestic and foreign price levels.) The initial exchange rate appreciation is driven by future expected interest rate differentials, and in the following periods, the exchange rate gradually depreciates back to its equilibrium level.

A shock to domestic inflation in the second row has a hump-shaped effect on annual CPI inflation, and thus on the nominal interest rate. The interest rate increase, together with an appreciated real exchange rate (since the domestic price level rises), drives output down to a minimum level after five quarters. Output remains persistently below its equilibrium for a total of eight quarters before the output gap is closed. Inflation is gradually forced back to target, with a slight undershooting. Interestingly, although the interest rate is raised, there is no initial nominal exchange rate appreciation: since the inflation disturbance is expected to be offset only gradually, the long-run price differential increases, resulting in an 
exchange rate depreciation towards a higher equilibrium level.

A shock to the risk premium in the third row produces a depreciation of the nominal exchange rate, which has an immediate effect on CPI inflation and hence the interest rate is increased. The nominal exchange rate then quickly appreciates, rapidly reducing CPI inflation and the interest rate. Since domestic prices are sticky, the nominal exchange rate depreciation is translated into a real exchange rate depreciation, which has an expansive effect on output, after an initial fall.

\section{Optimized simple policy rules and exchange rate model uncertainty}

We now turn to the main objective of the paper: the performance and robustness of different policy rules in the various versions of our model. The analysis proceeds in three steps: we begin by discussing the optimized policy rules for the baseline model; we then demonstrate how these optimized rules vary as the model changes; and we end by analyzing how well the optimized rules for the baseline model perform when the true model is different from the baseline.

In an open economy, it may seem natural to use the exchange rate as an indicator for monetary policy and include it in the central bank's policy rule. As described in previous sections, the exchange rate enters as an important forcing variable for all endogenous variables in the model, and is a central element of the monetary transmission mechanism. At the same time, the exchange rate is highly endogenous: it is the price that equilibrates the demand and supply of foreign and domestic currency, and as such it is very sensitive to the forces determining supply and demand. If monetary policy is already responding to these underlying forces to an appropriate degree, there may be no role for the exchange rate as an extra indicator. ${ }^{19}$ The question thus boils down to whether the inflation and output gaps are sufficient indicators for the state of the small open economy.

\subsection{Optimized policy rules in the baseline model}

We begin by optimizing the four policy rules in the baseline model. Table 3 shows the obtained policy rules, and Table 4 shows the resulting unconditional variances of some important variables, as well as the value of the loss function (23). ${ }^{20}$ (The

\footnotetext{
${ }^{19}$ See also Taylor (2000).

${ }^{20}$ The optimized coefficients are obtained using the Constrained Optimization (CO) routines in Gauss, which solve a nonlinear programming problem using the sequential quadratic programming
} 
Table 3: Optimized policy rules in baseline model

\begin{tabular}{lccccc}
\hline \hline Rule & \multicolumn{4}{c}{ Coefficient on } \\
\cline { 2 - 6 } & $y_{t}$ & $\bar{\pi}_{t}$ & $\Delta s_{t}$ & $\hat{q}_{t}$ & $\Delta \hat{q}_{t}$ \\
\hline$T$ & 1.67 & 1.93 & - & - & - \\
$\Delta S$ & 1.67 & 1.93 & -0.17 & - & - \\
$Q$ & 1.67 & 1.93 & - & 0.04 & - \\
$\Delta Q$ & 1.67 & 1.93 & - & - & -0.21 \\
\hline
\end{tabular}

Note: Simple rule coefficients that minimize the objective function (23) with $\lambda=0.5, \nu=0.1$. Output and inflation coefficients optimized for Taylor rule, exchange rate coefficients optimized for each rule.

column marked "Relative loss" in Table 4 shows the loss as percent of that from the optimal unrestricted policy under commitment, rule $C$.) We first note that the optimized coefficients in the Taylor rule $(T)$ are larger than in the standard Taylor (1993) rule: 1.67 on the output gap and 1.93 on annual CPI inflation. This rule also performs very well in comparison with the optimal unrestricted rule under commitment (rule $C$ ): the loss in the second row of Table 4 is only around 8 percent higher than in the first row. Most importantly, including the exchange rate variables in the policy rule yields only small improvements relative to the $T$ rule: there are only marginal decreases in the value of the loss function in the next three rows, and the $Q$ rule gives almost no improvement at all. Interestingly, the optimized coefficients on the rate of real and nominal exchange rate depreciation in Table 3 are negative: the central bank thus responds to a depreciation of the exchange rate by raising the interest rate less than under the $T$ rule. ${ }^{21}$ The coefficient on the level of the real exchange rate is positive, however, although small.

That extending the Taylor rule with an exchange rate variable gives little improvement in terms of the stability of the economy is a common result in the literature (see Taylor, 2000, for an overview). However, the result that the optimized coefficients on the rate of exchange rate depreciation are negative is less common,

method. As mentioned earlier, including the lagged interest rate in the policy rules has no significant effects on the results, as it obtains a fairly small optimized coefficient. This is partly due to the low degree of forward-looking behavior in the model. As shown by Woodford (1999), optimal policy in a forward-looking model (under commitment) displays a large degree of interest rate inertia, so including a lagged interest rate in a suboptimal rule can often be beneficial. But this result hinges crucially on the degree of forward-looking behavior: with the low weight on forward-looking behavior in our model, there are only small gains from introducing more inertia in the policy rule. Furthermore, since our policy rule includes the annual inflation rate, there is already some inertia in the rule. (See also Nessén and Vestin, 2000.)

${ }^{21}$ Note that the total response is still to raise the interest rate in the face of an exchange rate depreciation, since the depreciation also increases CPI inflation. If we instead use domestic inflation in the policy rules, the optimized coefficients on the exchange rate variables are always positive. 
Table 4: Unconditional variances of important variables and value of loss function in baseline model

\begin{tabular}{lccccccccc}
\hline \hline Rule & \multicolumn{7}{c}{ Variance of } & Loss & Relative loss \\
\cline { 2 - 7 } & $y_{t}$ & $\bar{\pi}_{t}$ & $\Delta s_{t}$ & $\hat{q}_{t}$ & $\Delta \hat{q}_{t}$ & $i_{t}$ & $\Delta i_{t}$ & & \\
\hline$C$ & 3.08 & 5.06 & 3.26 & 4.01 & 3.34 & 10.98 & 4.47 & 7.04 & 100.00 \\
$T$ & 3.44 & 5.16 & 2.95 & 4.22 & 3.11 & 12.78 & 7.03 & 7.58 & 107.66 \\
$\Delta S$ & 3.31 & 5.22 & 3.03 & 4.15 & 3.17 & 12.42 & 6.82 & 7.55 & 107.27 \\
$Q$ & 3.46 & 5.15 & 2.90 & 4.23 & 3.07 & 12.72 & 7.03 & 7.58 & 107.66 \\
$\Delta Q$ & 3.28 & 5.20 & 3.05 & 4.10 & 3.18 & 12.53 & 6.93 & 7.53 & 107.39 \\
\hline
\end{tabular}

Note: Loss calculated from equation (23), with $\lambda=0.5, \nu=0.1$. Relative loss expressed as percent of loss from optimal unrestricted policy under commitment (rule $C$ ).

and may seem counterintuitive. It therefore warrants some further consideration.

First note that in the baseline model with rational expectations, the solution for the nominal exchange rate is given by iterating on equation (9), with $\hat{s}_{t+1, t}=s_{t+1 \mid t}$, resulting in

$$
s_{t}=-\frac{1}{4} \sum_{j=0}^{\infty}\left[i_{t+j \mid t}-i_{t+j \mid t}^{f}\right]+\sum_{j=0}^{\infty} u_{t+s \mid t}^{s}+\lim _{j \rightarrow \infty}\left(p_{t+j \mid t}^{d}-p_{t+j \mid t}^{f}\right),
$$

where we have used the definition of the real exchange rate and the long-run PPP condition $\lim _{j \rightarrow \infty} q_{t+j \mid t}=0$. Thus, the current exchange rate depends on the sum of expected future interest rate differentials corrected for the risk premium and the equilibrium price level differential. ${ }^{22}$ Although an upward revision of expected future interest rate differentials leads to an instantaneous exchange rate appreciation, a current positive interest rate differential means that the exchange rate is expected to depreciate:

$$
\Delta s_{t+1 \mid t}=\frac{1}{4}\left[i_{t}-i_{t}^{f}\right]-u_{t}^{s} .
$$

Hence, a monetary policy rule that induces a higher interest rate (differential) will increase the expected rate of depreciation.

For these reasons, forward-looking behavior in the exchange rate market introduces a potential conflict between the direct exchange rate channel (affecting CPI inflation via imported inflation) and the other channels of monetary policy. A depreciation caused by a high interest rate differential feeds directly into CPI inflation, which induces an even higher interest rate differential, leading to an even greater

\footnotetext{
${ }^{22}$ This price level effect may be quite substantial, depending on the type of shock hitting the economy. In Figure 1 shocks to domestic inflation have the strongest long-run nominal exchange rate response, as the loss function only provides incentives for bringing the inflation rate back to its pre-shock value, leading to base drift in the price level.
} 
rate of depreciation, etc. As a result, when the central bank responds separately to the exchange rate depreciation by raising the interest rate further, the interest rate and the exchange rate become more volatile, leading to larger volatility also in the real economy.

However, this effect can be reduced by letting monetary policy respond negatively to the rate of exchange rate depreciation, thus reducing interest rate and exchange rate volatility. An expected positive interest rate differential then first produces an immediate appreciation, leading to an increased interest rate. But the negative policy response to the following depreciation implies that the interest rate is below that implied by the Taylor rule during the time of depreciation. The expected future sum of interest rate differentials are then smaller than under the Taylor rule and the exchange rate closer to its equilibrium rate. As a consequence, the exchange rate and the interest rate are both more stable, leading to less output volatility, although at the price of slightly higher volatility in inflation.

This conflict between the direct and indirect exchange rate channels seems to be present also in other studies. Svensson (2000) compares a Taylor rule including domestic inflation with one including CPI inflation, and thus with a positive coefficient (of 0.45 ) on the change in the nominal exchange rate. In that model, the latter rule leads to a lower variance in CPI inflation but higher variance in output. Likewise, Taylor (1999) includes the current and lagged real exchange rate in a policy rule for Germany, France and Italy (with coefficients 0.25 and -0.15 , respectively). In France and Italy this lowers the variances of both output and inflation, but in Germany the variance in output increases. Thus, there seems to be a trade-off in both Svensson's model and in Taylor's model for Germany: a positive response to the exchange rate increases the variance in output and decreases the variance in inflation, just as in our model. ${ }^{23}$ Whether this trade-off makes the central bank prefer a positive or a negative response to the exchange rate naturally depends both on parameter values and on the central bank's preferences. In our baseline specification, the central bank prefers a negative response, allowing for a higher variance of inflation, but a lower variance in output (and in the interest rate). As we shall see below, the conflict is less severe when the degree of exchange rate pass-through is small (since the effects of the exchange rate on CPI inflation are more sluggish) and when exchange rate expectations are predominantly backward-looking (since the exchange rate then is less sensitive to the interest rate differential). Thus, in

\footnotetext{
${ }^{23}$ If we force the central bank to respond positively to changes in the real exchange rate, this is exactly what happens.
} 
Figure 2: Exchange rate coefficients in different model configurations

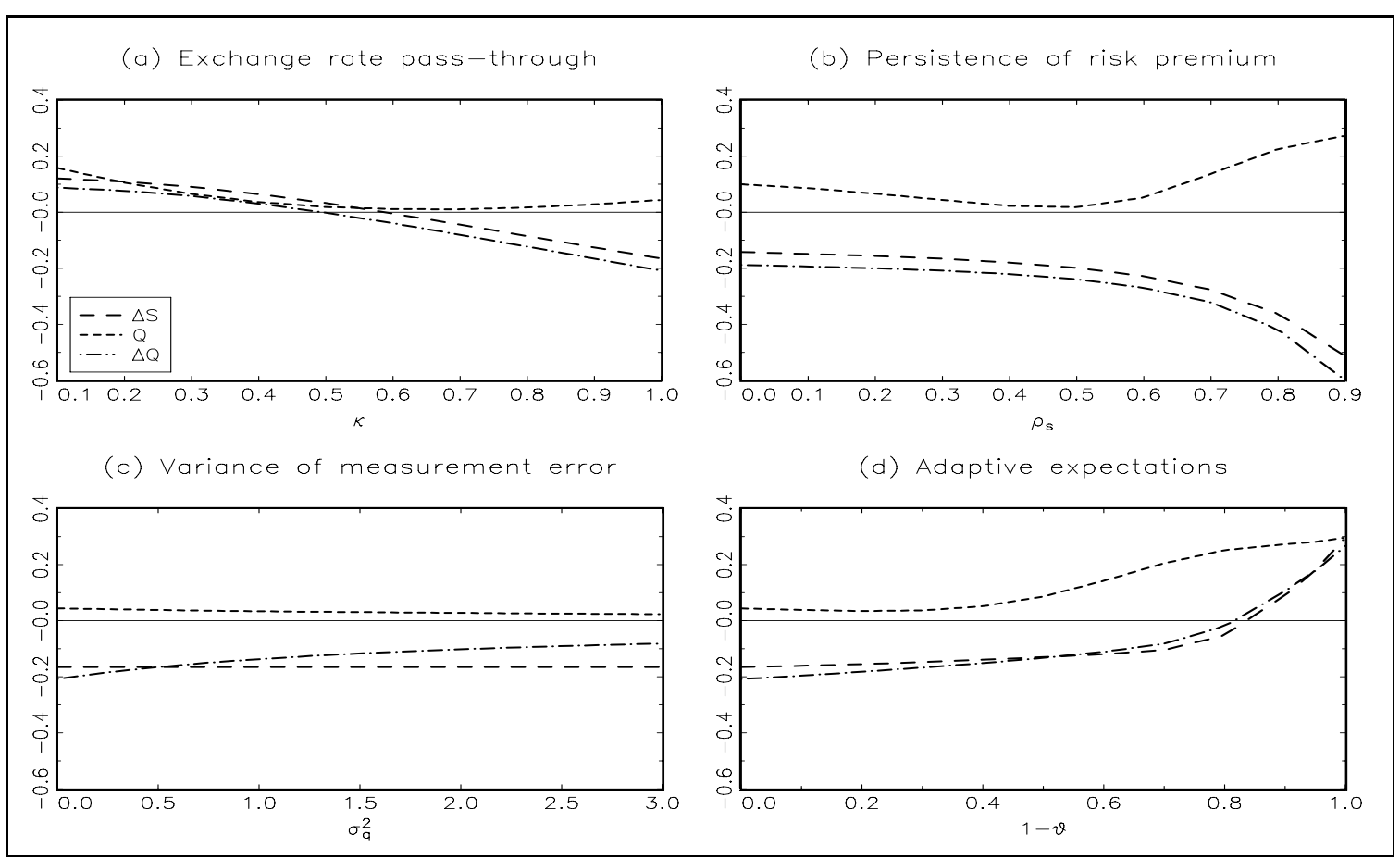

Note: Optimized exchange rate coefficients, given output and inflation coefficients.

some configurations of the model the optimized coefficients on the rate of exchange rate depreciation are positive.

\subsection{Optimized policy rules in the different models}

The optimized policy rule coefficients are of course sensitive to the exact specification of the model. Figure 2 shows how the exchange rate coefficients vary in the different model configurations. ${ }^{24}$ The long-dashed lines represent the coefficient in the $\Delta S$ rule, the short-dashed lines represent the $Q$ rule, and the dashed-dotted lines represent the coefficient in the $\Delta Q$ rule.

The degree of exchange rate pass-through plays an important role in the model, since it determines the direct effects of exchange rate movements on CPI inflation, and the importance of the conflict between the direct exchange rate channel and the other transmission channels. As the speed of pass-through $(\kappa)$ falls in panel $(a)$, the coefficients on the exchange rate depreciation increase, and with a rate of passthrough below $\kappa=0.5$ the coefficients are positive. As the direct exchange rate channel becomes more sluggish (when $\kappa$ falls) the conflict between this channel and the other channels of monetary policy becomes less important. There is therefore

\footnotetext{
${ }^{24}$ The coefficients on output and inflation are shown in Figure C.1 in Appendix C.
} 
less of a need for a negative response to the exchange rate variables, and the central bank instead tightens policy more when the nominal exchange rate depreciates to avoid the indirect inflationary effects. ${ }^{25}$ The coefficient on the level of the real exchange rate is positive for all degrees of pass-through.

The persistence of the risk premium determines the relative importance of risk premium shocks in creating volatility in the economy. Increasing the persistence of the risk premium $\left(\rho_{s}\right)$ in panel $(b)$ the coefficients on the change in the nominal and real exchange rate fall further, whereas that on the level of the real exchange rate first falls slightly and then increases. When the risk premium becomes more persistent, its effects on the economy become more long-lived, and risk premium shocks become a more important source of volatility. Thus, the motivation for offsetting such shocks becomes stronger, and the coefficients on the exchange rate variables all increase (in absolute terms).

The error when measuring the real exchange rate affects the desirability of responding to the real exchange rate. Varying its variance in panel $(c)$ thus only affects the coefficients on the real exchange rate: as the variance increases, the coefficients on both the level and the change of the real exchange rate approach zero. This result is in line with the results of Orphanides (1998) and Rudebusch (2000b) concerning output gap uncertainty: the optimal response to a noisy indicator becomes smaller as the amount of noise increases. ${ }^{26}$

Finally, the weight on adaptive expectations determines the degree to which the foreign exchange market is forward-looking, and thus the effects of interest rate changes on the exchange rate. Introducing adaptive expectations in panel $(d)$ initially has little effect on the exchange rate coefficients, but as the weight on rational expectations becomes small (so $1-\vartheta$ becomes large), the exchange rate coefficients increase and, again, eventually become positive. When the exchange rate is predominantly backward-looking, it is less sensitive to the expected future interest rate differential, and therefore the incentives for dampening exchange rate volatility with a negative response to the rate of depreciation become less important.

Appendix A describes in detail the implications for the exchange rate of combining adaptive and rational expectations. The main insight is that as long as the weight on adaptive expectations is not too large, the implications of rational expectations still dominate and the model properties are kept by and large. A moderate

\footnotetext{
${ }^{25}$ Figure C.1 in Appendix C shows that the optimized coefficient on inflation decreases with the speed of pass-through, much for the same reason.

${ }^{26}$ See also Svensson and Woodford (2000) and Swanson (2000) for analyses of the optimal response to noisy indicators.
} 
Figure 3: Value of loss function with optimized simple rules in different model configurations

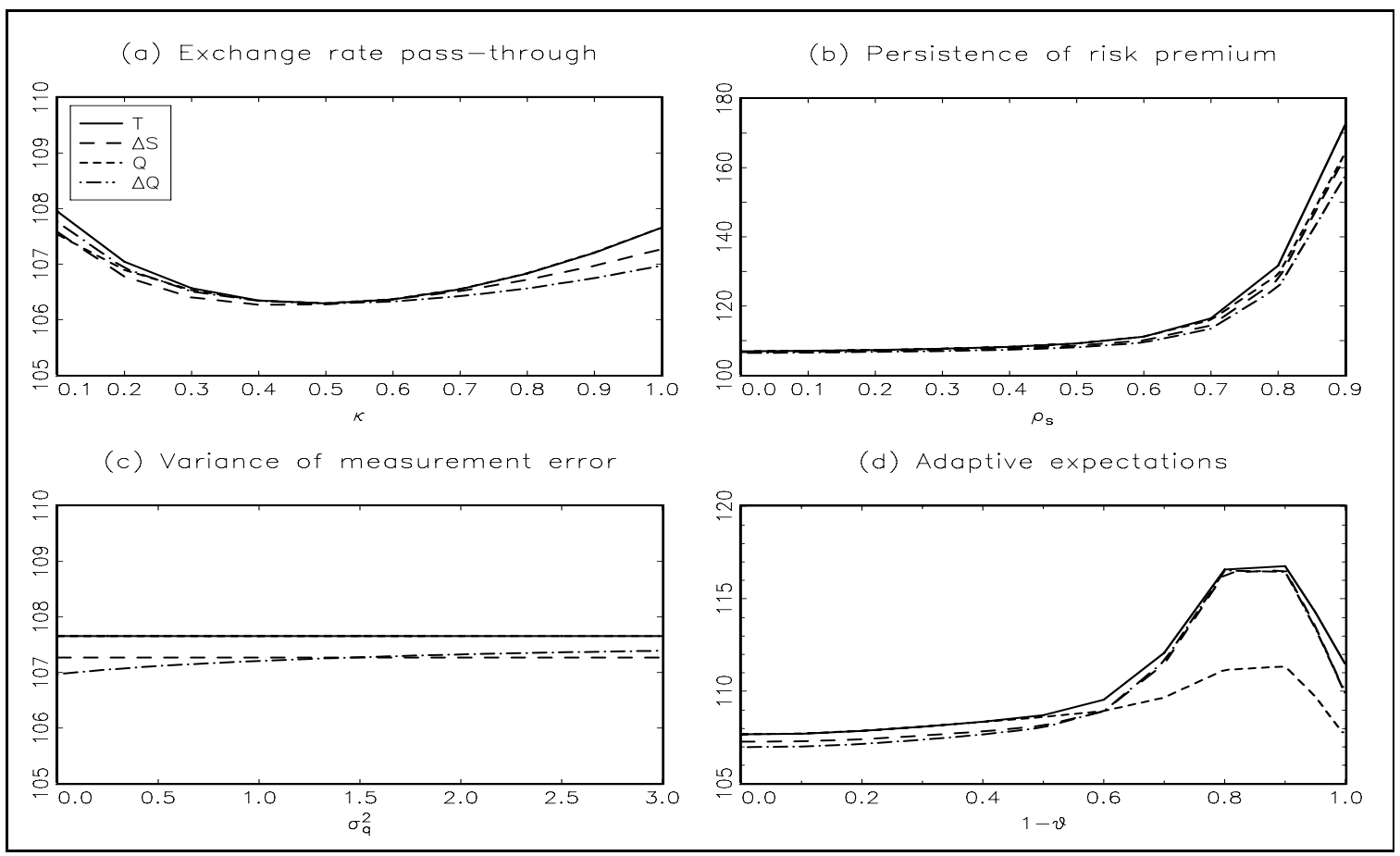

Note: Value of loss function as percent of loss from optimal unrestricted policy under commitment.

weight on adaptive expectations introduces a positive autoregressive component in the exchange rate process, without changing the fact that the exchange rate reacts to the entire expected sum of future interest rate differentials, so the conflict is still important. In the fully adaptive case, however, there is no conflict as the exchange rate is given by

$$
s_{t}=s_{t, t-1}^{A}-\frac{1}{4 \xi}\left[i_{t}-i_{t}^{f}\right]+\frac{1}{\xi} u_{t}^{s}
$$

so only the current interest rate differential and risk premium matter for the exchange rate. As a consequence, the optimized exchange rate coefficients are all positive.

Figure 3 shows the loss resulting from each policy rule when the model is altered. (A solid line here represents the $T$ rule.) Depending on model configuration, the relative performance of the policy rules also varies. ${ }^{27}$ Nevertheless, the differences in loss are still fairly small: there are thus no large gains to be made from including the exchange rate in the policy rule in any configuration. Furthermore, the loss relative to the optimal unrestricted rule under commitment is small, unless the persistence

\footnotetext{
${ }^{27}$ The $T$ rule of course always yields the worst outcome, since the exchange rate rules are generalizations of the Taylor rule.
} 
of the risk premium is close to one. In sum, the simple Taylor rule seems to be rather efficient in stabilizing the open economy, regardless of the exact specification of the exchange rate model.

\subsection{Robustness of the baseline policy rules in the different models}

Having discussed the optimized policy rules when the central bank knows the true model, we now turn to the case of model uncertainty. In this section we assume that the central bank is unaware of the true model determining the exchange rate or its effects on the economy, but optimizes its policy rule for the baseline model (which could be interpreted as the most likely model, as it is similar to conventional open economy models). We then calculate the outcome if the true model turns out to be different from the baseline. This way we hope to say something about the risks facing policymakers and about the robustness of the alternative policy rules. ${ }^{28}$

Figure 4 shows the loss resulting from using the optimized baseline rules of Table 3 in the different model configurations. (The loss is expressed as percent of the loss from the optimal unrestricted policy rule under commitment in each model.) Again we note that the variation in loss is fairly small, except in some extreme parameterizations where the optimized coefficients differ substantially from those in the baseline rules. There are, however, some differences in the relative performance of the policy rules.

Varying the degree of exchange rate pass-through in panel $(a)$ has no important effects on the outcome using the baseline rule. The $\Delta Q$ rule performs slightly better than the $\Delta S$ rule while the $T$ and $Q$ rules give a worse outcome. (Now, of course, the $T$ rule may well perform better than the other rules, since the rules are optimized in one model and evaluated in another. Also, the $T$ and $Q$ rules lead to similar outcomes since the coefficient on the real exchange rate in the $Q$ rule is very small.)

Increasing the persistence of the risk premium in panel $(b)$ increases the loss under all rules. When the risk premium is very persistent, all policy rules perform considerably worse than the optimal unrestricted rule under commitment: when $\rho_{s}=0.9$ the simple rules lead to a loss which is three times larger than that under the optimal unrestricted rule and almost twice as large as that of the optimized simple rules in Figure 3. Nevertheless, there are no large differences between the

\footnotetext{
${ }^{28}$ Note that this modeling strategy does not put the central bank on the same footing as the other agents in the model, since these know the true model while the central bank does not. We thus look at the robustness of policy rules in the sense of McCallum $(1988,1999)$ and Rudebusch (2000a) rather than in the sense of robust control theory (e.g., Hansen and Sargent, 2000), where all agents in the model share the same doubts about the true model specification.
} 
Figure 4: Value of loss function using baseline simple policy rules in different model configurations

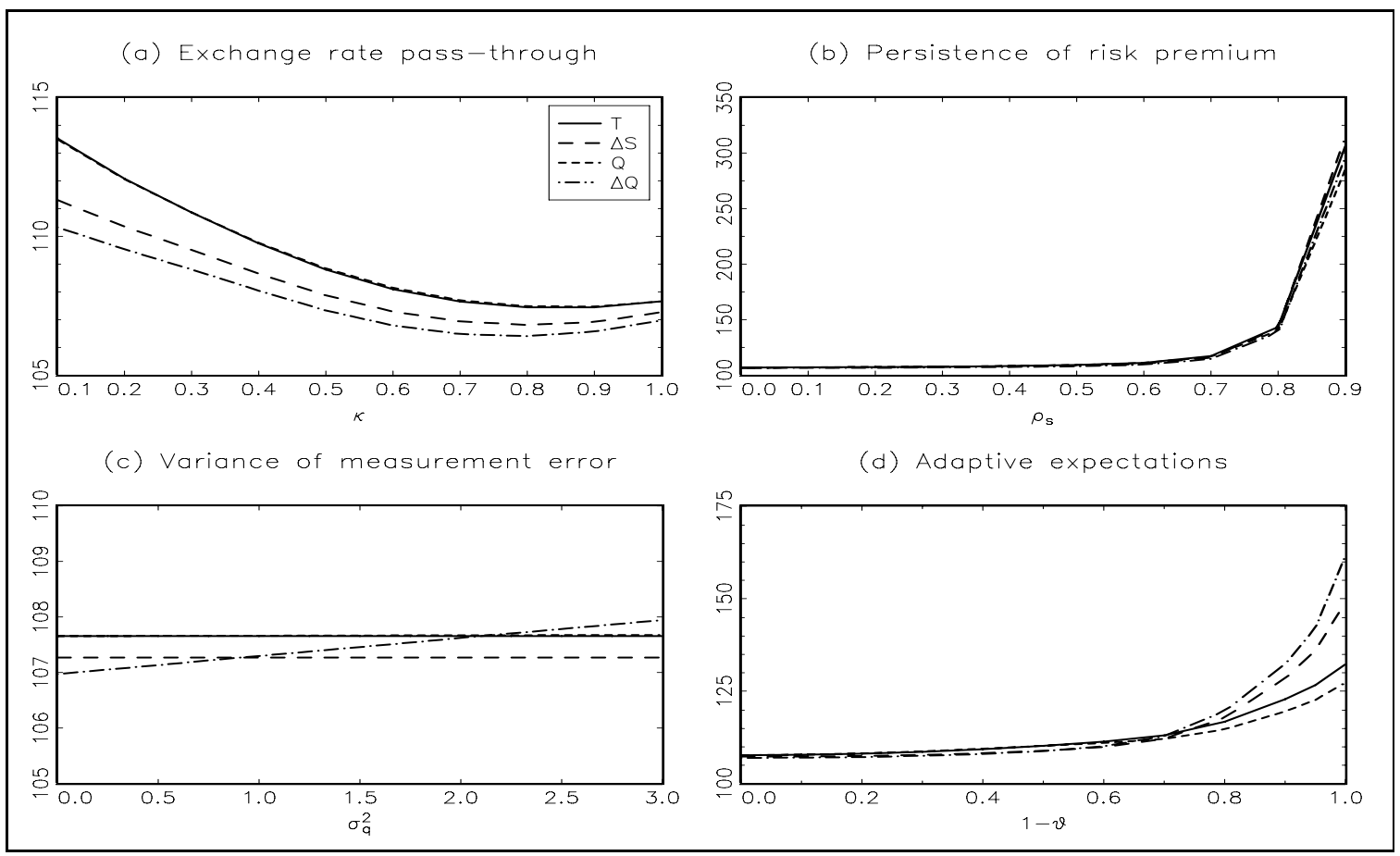

Note: Value of loss function as percent of loss from optimal unrestricted policy under commitment in each configuration.

policy rules.

Increasing the variance of the measurement error in panel $(c)$ worsens the performance of both real exchange rate rules. Although the $\Delta Q$ rule performs slightly better than the other rules when the measurement error is small, its performance deteriorates as the amount of noise increases, and when the variance of the measurement error is large, it performs worse than the other rules. Again, however, the differences are fairly small overall, also compared with the outcomes of the optimized policy rules.

Finally, under adaptive expectations in panel $(d)$, there is more variation in the outcomes, and larger differences across the rules, especially when expectations are predominantly adaptive. For large weights on adaptive expectations, the $\Delta S$ and $\Delta Q$ rules perform considerably worse than the $Q$ and $T$ rules, and the $Q$ rule performs slightly better than the $T$ rule.

In conclusion, although all rules are fairly robust to model uncertainty, the $T$ rule and the $Q$ rule (which is very similar to the T rule) are more robust to uncertainty about the formation of exchange rate expectations. Thus, the traditional Taylor rule seems both efficient and robust as a guide for monetary policy in an open economy. 


\section{$5 \quad$ Summary and conclusions}

The exchange rate is an important part of the monetary transmission mechanism in an open economy. Therefore, it may seem natural to include some measure of the exchange rate in the central bank's policy rule, in order to better stabilize the economy. At the same time, the model determining the exchange rate and its effects on the economy is inherently uncertain. This paper therefore analyzes the gains from including the exchange rate in an optimized Taylor rule, how these gains vary with the specification of the exchange rate model, and how robust different policy rules are to uncertainty about the exchange rate model.

We find that including the exchange rate in an optimized Taylor rule gives little improvement in terms of economic stability. This is true in most configurations of the exchange rate model. Furthermore, the policy rules that respond to the real or nominal rate of exchange rate depreciation are slightly more sensitive to model uncertainty than is the traditional Taylor rule, in particular with respect to the formation of exchange rate expectations. Thus, our results indicate that a traditional Taylor rule responding optimally to CPI inflation and the output gap may be sufficient to stabilize also a small open economy, and it is also robust to exchange rate model uncertainty.

This paper has concentrated on uncertainty concerning the exchange rate model. Future work could extend the analysis by including other types of uncertainty, e.g., concerning the equilibrium real interest rate or the natural level of output. Another extension would be to use robust control techniques (see Hansen and Sargent, 2000) in order to design robust rules for monetary policy in an open economy. Since the exchange rate model is perhaps the most uncertain part of the monetary transmission mechanism, we believe that the robustness of policy rules to exchange rate model uncertainty is central to monetary policy research in open economies. 


\section{A Exchange rate dynamics under adaptive expectations}

Under adaptive expectations, the equation system to be solved is given by

$$
\begin{aligned}
s_{t} & =\vartheta s_{t+1 \mid t}+(1-\vartheta) s_{t+1, t}^{A}-\frac{1}{4}\left[i_{t}-i_{t}^{f}\right]+u_{t}^{s}, \\
s_{t+1, t}^{A} & =(1-\xi) s_{t}+\xi s_{t, t-1}^{A} .
\end{aligned}
$$

Equation (A2) may be written as

$$
s_{t+1, t}^{A}=(1-\xi) s_{t}+\xi L s_{t+1, t}^{A},
$$

where $L$ is the lag operator. Isolating for the next-period expected exchange rate yields

$$
s_{t+1, t}^{A}=\frac{1-\xi}{1-\xi L} s_{t},
$$

and substituting the expected rate into equation (A1) yields

$$
\begin{aligned}
s_{t}=\vartheta s_{t+1 \mid t}+(1-\vartheta) \frac{1-\xi}{1-\xi L} s_{t}-\frac{1}{4}\left[i_{t}-i_{t}^{f}\right]+u_{t}^{s}, \\
\begin{aligned}
(1-\xi L) s_{t}= & (1-\xi L) \vartheta s_{t+1 \mid t}+(1-\vartheta)(1-\xi) s_{t} \\
& -\frac{1}{4}(1-\xi L)\left[i_{t}-i_{t}^{f}\right]+(1-\xi L) u_{t}^{s},
\end{aligned} \\
\begin{aligned}
(\vartheta+\xi-\vartheta \xi) s_{t}= & \xi s_{t-1}+\vartheta s_{t+1 \mid t}-\xi \vartheta s_{t \mid t-1} \\
& -\frac{1}{4}\left[i_{t}-i_{t}^{f}\right]+\frac{1}{4} \xi\left[i_{t-1}-i_{t-1}^{f}\right]+u_{t}^{s}-\xi u_{t-1}^{s}
\end{aligned} \\
s_{t}=\Theta_{1}^{A} s_{t-1}+\Theta_{2}^{A} s_{t+1 \mid t}+\Theta_{3}^{A} s_{t \mid t-1}+\omega_{t}^{A},
\end{aligned}
$$

where

$$
\begin{aligned}
\Theta_{1}^{A}= & \frac{\xi}{\vartheta+(1-\vartheta) \xi_{A}}, \\
\Theta_{2}^{A}= & \frac{\vartheta}{\vartheta+(1-\vartheta) \xi}, \\
\Theta_{3}^{A}= & \frac{-\vartheta \xi}{\vartheta+\left(1-\vartheta_{R}\right) \xi}, \\
\omega_{t}^{A}= & \frac{1}{\vartheta+\left(1-\vartheta_{R}\right) \xi} \\
& \times\left\{-\frac{1}{4}\left[i_{t}-i_{t}^{f}\right]+\frac{1}{4} \xi\left[i_{t-1}-i_{t-1}^{f}\right]+u_{t}^{s}-\xi u_{t-1}^{s}\right\} .
\end{aligned}
$$


The characteristic equation associated with (A8) is given by

$$
\Theta_{2}^{A} \mu^{2}-\left(1-\Theta_{3}^{A}\right) \mu+\Theta_{1}^{A}=0
$$

which solves for the backward and forward roots respectively keeping in mind the restriction on the $\Theta^{A}$ 's,

$$
\begin{aligned}
& \mu_{B}=\frac{\left(\Theta_{1}^{A}+\Theta_{2}^{A}\right)-\sqrt{\left(\Theta_{2}^{A}-\Theta_{1}^{A}\right)^{2}}}{2 \Theta_{2}^{A}} \\
& \mu_{F}=\frac{\left(\Theta_{1}^{A}+\Theta_{2}^{A}\right)+\sqrt{\left(\Theta_{2}^{A}-\Theta_{1}^{A}\right)^{2}}}{2 \Theta_{2}^{A}} .
\end{aligned}
$$

The solution to equation (A7) can now be written as

$$
\begin{aligned}
s_{t}= & \mu_{B} s_{t-1}+\left(1-\Theta_{2}^{A} \mu_{B}\right)^{-1} \sum_{i=0}^{\infty}\left(\mu_{F}\right)^{-i} \omega_{t+i \mid t}^{A} \\
& +\frac{\left(1-\Theta_{2}^{A}-\Theta_{1}^{A}\right)}{\Theta_{2}^{A} \mu_{F}\left(1-\Theta_{2}^{A} \mu_{B}\right)} \sum_{i=0}^{\infty}\left(\mu_{F}\right)^{-i} \omega_{t+i \mid t-1}^{A} \\
& +\left(1-\mu_{B}\right) \lim _{j \rightarrow \infty}\left(p_{t+j \mid t}-p_{t+j \mid t}^{f}\right) .
\end{aligned}
$$

In order to explain the slow effects of changes in $\vartheta$ on the optimized exchange rate coefficients, first note that the forward root, $\mu_{F}$, equals unity for $\vartheta \geq \xi$, which means that the expected future sum of the risk-premium corrected interest rate differentials remain undiscounted when the degree of adaptive expectations is not too large. Thus, there is a relatively strong feedback to the exchange rate from a future persistent interest rate movement. This implies that the initial reaction to exchange rate may be quite substantial as in the pure rational expectations case. As the weight on adaptive expectations increases, the persistence $\left(\mu_{B}\right)$ in the exchange rate process increases and the initial reaction to the exchange rate is exacerbated.

The rationally expected rate of depreciation can be expressed as in the rational expectations case, assuming $\vartheta \geq \xi$, as

$$
\begin{aligned}
\Delta s_{t+1 \mid t}= & \mu_{B} \Delta s_{t}+\left(1-\Theta_{2}^{A} \mu_{B}\right)^{-1}\left\{\frac{1}{4}\left[i_{t}-i_{t}^{f}\right]-u_{t}^{s}\right\} \\
& +\frac{\left(1-\Theta_{2}^{A}-\Theta_{1}^{A}\right)}{\Theta_{2}^{A}\left(1-\Theta_{2}^{A} \mu_{B}\right)}\left\{\frac{1}{4}\left[i_{t-1}-i_{t-1}^{f}\right]-u_{t-1}^{s}\right\} \\
& +\left(1-\mu_{B}\right) \lim _{j \rightarrow \infty}\left(\pi_{t+j}-\pi_{t+j}^{f}\right) .
\end{aligned}
$$

For conventional parameter values, the expected next-period rate of depreciation is determined mainly by the current interest rate differential. However, as the rate 
of persistence increases, the direction of the current period exchange-rate movement has an increasingly stronger influence upon the future movement. An initial exchange rate appreciation, e.g., due to an upward revision of future interest rate differentials, produces expectations of further appreciations. This effect gradually dies out as the persistence and the rate of movement indicated by the interest rate differentials dominate and pull in the opposite direction. The persistence now exacerbates the depreciation. In this situation a given interest rate differential exerts a greater influence on inflation through the direct exchange rate channel than in the rational expectations case. The inflation coefficient is therefore even more inappropriate and the optimal exchange-rate coefficient stays negative for very large weights on adaptive expectations. In the limit, however, when $\vartheta=0$, the exchange rate process is given by

$$
s_{t}=s_{t-1}-\frac{1}{\xi}\left\{\frac{1}{4}\left[i_{t}-i_{t}^{f}\right]+u_{t}^{s}\right\}+\frac{1}{4}\left[i_{t-1}-i_{t-1}^{f}\right]+u_{t-1}^{s},
$$

which implies that there is no response of the exchange rate to the future expected interest rate differential and a positive current interest rate differential implies a gradual appreciation, under the condition that the interest rate differential in the previous period does not deviate too much from the current one (the second term will dominate the third). There is hence no conflict between the interest rate channel and exchange rate channels; an interest rate increase implies a contractionary policy through all channels.

\section{B Model appendix}

\section{B.1 Setting up the model}

To solve the model, we first formulate it on state-space form. First, define the real variable

$$
q_{t+1}^{A} \equiv s_{t+1, t}^{A}+p_{t+1}^{f}-p_{t+1}^{d}
$$

and use in (12) together with (14) to get

$$
q_{t+1}^{A}-p_{t+1}^{f}+p_{t+1}^{d}=(1-\xi) q_{t}+\xi q_{t}^{A}-p_{t}^{f}+p_{t}^{d}
$$

Solving for $q_{t+1}^{A}$ yields

$$
\begin{aligned}
q_{t+1}^{A} & =(1-\xi) q_{t}+\xi q_{t}^{A}+\pi_{t+1}^{f}-\pi_{t+1}^{d} \\
& =(1-\xi) q_{t}+\xi q_{t}^{A}+\rho_{\pi f} \pi_{t}^{f}+\varepsilon_{t+1}^{\pi f}-\pi_{t+1 \mid t}^{d}-\varepsilon_{t+1}^{\pi}
\end{aligned}
$$


Also,

$$
s_{t+1, t}^{A}=(1-\xi) q_{t}+\xi q_{t}^{A}+p_{t}^{d}-p_{t}^{f} .
$$

Use (14), (11) and (B4) in (9) to eliminate the nominal exchange rate:

$$
\begin{aligned}
q_{t} & +p_{t}^{d}-p_{t}^{f} \\
& =\vartheta\left[q_{t+1 \mid t}+p_{t+1 \mid t}^{d}-p_{t+1 \mid t}^{f}\right]+(1-\vartheta)\left[(1-\xi) q_{t}+\xi q_{t}^{A}+p_{t}^{d}-p_{t}^{f}\right] \\
& +\frac{1}{4}\left[i_{t}^{f}-i_{t}\right]+u_{t}^{s}
\end{aligned}
$$

and rearrange to get

$$
\begin{aligned}
\Omega_{q} q_{t} & =\vartheta q_{t+1 \mid t}+(1-\vartheta) \xi q_{t}^{A}+\vartheta\left[p_{t+1 \mid t}^{d}-p_{t+1 \mid t}^{f}\right]-\vartheta\left[p_{t}^{d}-p_{t}^{f}\right] \\
& +\frac{1}{4}\left[i_{t}^{f}-i_{t}\right]+u_{t}^{s}
\end{aligned}
$$

where

$$
\begin{aligned}
\Omega_{q} & \equiv 1-(1-\vartheta)(1-\xi) \\
& =\vartheta+(1-\vartheta) \xi .
\end{aligned}
$$

Now use

$$
\begin{aligned}
p_{t}^{d} & =\pi_{t}^{d}+p_{t-1}^{d}, \\
p_{t}^{f} & =\pi_{t}^{f}+p_{t-1}^{f}, \\
p_{t+1 \mid t}^{d} & =\pi_{t+1 \mid t}^{d}+p_{t}^{d} \\
& =\pi_{t+1 \mid t}^{d}+\pi_{t}^{d}+p_{t-1}^{d}, \\
p_{t+1 \mid t}^{f} & =\pi_{t+1 \mid t}^{f}+p_{t}^{f} \\
& =\left(1+\rho_{\pi f}\right) \pi_{t}^{f}+p_{t-1}^{f},
\end{aligned}
$$

to eliminate the non-stationary price levels and solve for $q_{t+1 \mid t}$ :

$$
\vartheta q_{t+1 \mid t}=\Omega_{q} q_{t}-(1-\vartheta) \xi q_{t}^{A}-\vartheta \pi_{t+1 \mid t}^{d}+\vartheta \rho_{\pi f} \pi_{t}^{f}-\frac{1}{4}\left[i_{t}^{f}-i_{t}\right]-u_{t}^{s} .
$$

Likewise, eliminate $s_{t}, p_{t}^{d}, p_{t}^{f}$ from (4):

$$
\begin{aligned}
\pi_{t}^{M} & =(1-\kappa) \pi_{t-1}^{M}+\kappa\left(\pi_{t}^{f}+q_{t}-q_{t-1}+\pi_{t}^{d}-\pi_{t}^{f}\right) \\
& =(1-\kappa) \pi_{t-1}^{M}+\kappa\left(q_{t}-q_{t-1}+\pi_{t}^{d}\right)
\end{aligned}
$$


Finally, lead (8) one period and combine with (6) and (7) to get

$$
\begin{aligned}
i_{t+1}^{f} & =g_{y f} y_{t+1}^{f}+g_{\pi f} \bar{\pi}_{t+1}^{f} \\
& =g_{y f} \rho_{y f} y_{t}^{f}+g_{\pi f}\left[\left(1+\rho_{\pi f}\right) \pi_{t}^{f}+\pi_{t-1}^{f}+\pi_{t-2}^{f}\right]+g_{y f} \varepsilon_{t+1}^{y f}+g_{\pi f} \varepsilon_{t+1}^{\pi f} .
\end{aligned}
$$

Then the equations for the 21 predetermined state variables are given by (10), (16), (B13), (6), (7), (B14), (B3), (15), the additional equations

$$
\begin{aligned}
& y_{t+1}=y_{t+1 \mid t}+\varepsilon_{t+1}^{y}, \\
& \pi_{t+1}^{d}=\pi_{t+1 \mid t}^{d}+\varepsilon_{t+1}^{\pi},
\end{aligned}
$$

and identities for $\varepsilon_{t}^{y}, \varepsilon_{t}^{\pi}, \pi_{t}^{d}, \pi_{t-1}^{d}, \pi_{t-2}^{d}, \pi_{t-1}^{M}, \pi_{t-2}^{M}, \pi_{t}^{f}, \pi_{t-1}^{f}, q_{t}$ and $i_{t}$.

The equations for the 3 forward-looking variables are given by (B12), and by (1) and (2) after taking expectations at $t$ and solving for $y_{t+2 \mid t}, \pi_{t+2 \mid t}$ :

$$
\begin{aligned}
\beta_{y} \varphi_{y} y_{t+2 \mid t} & =y_{t+1 \mid t}-\beta_{y}\left(1-\varphi_{y}\right) y_{t}+\beta_{r} i_{t}-4 \beta_{r} \pi_{t+1 \mid t}^{d}-\beta_{q} q_{t}-\beta_{y f} y_{t}^{f} \\
\varphi_{\pi} \pi_{t+2 \mid t}^{d} & =\pi_{t+1 \mid t}^{d}-\left(1-\varphi_{\pi}\right) \pi_{t}^{d}-\gamma_{y} y_{t+1 \mid t}-\gamma_{q} q_{t+1 \mid t} .
\end{aligned}
$$

Using the predetermined state variables and the forward-looking variables, we can calculate CPI inflation, the change in the nominal exchange rate and the change in the observed real exchange rate as

$$
\begin{aligned}
\pi_{t} & =(1-\eta) \pi_{t}^{d}+\eta \pi_{t}^{M} \\
& =(1-\eta) \pi_{t}^{d}+\eta\left[(1-\kappa) \pi_{t-1}^{M}+\kappa\left(q_{t}-q_{t-1}+\pi_{t}^{d}\right)\right] \\
\Delta s_{t} & =q_{t}-q_{t-1}+\pi_{t}^{d}-\pi_{t}^{f}, \\
\Delta \hat{q}_{t} & =q_{t}+u_{t}^{q}-\hat{q}_{t-1} .
\end{aligned}
$$

The annual domestic and CPI inflation rates are given by

$$
\begin{aligned}
\bar{\pi}_{t}^{d} & =\sum_{\tau=0}^{\tau=3} \pi_{t-\tau}^{d} \\
\bar{\pi}_{t} & =(1-\eta)\left[\pi_{t}^{d}+\pi_{t-1}^{d}+\pi_{t-2}^{d}+\pi_{t-3}^{d}\right] \\
& +\eta\left[(1-\kappa) \pi_{t-1}^{M}+\kappa\left(q_{t}-q_{t-1}+\pi_{t}^{d}\right)+\pi_{t-1}^{M}+\pi_{t-2}^{M}+\pi_{t-3}^{M}\right] \\
& =(1-\eta+\eta \kappa) \pi_{t}^{d}+(1-\eta)\left[\pi_{t-1}^{d}+\pi_{t-2}^{d}+\pi_{t-3}^{d}\right] \\
& +\eta(2-\kappa) \pi_{t-1}^{M}+\eta\left[\pi_{t-2}^{M}+\pi_{t-3}^{M}\right]+\eta \kappa\left[q_{t}-q_{t-1}\right] .
\end{aligned}
$$

Then we can define 10 potential goal variables (or variables to be included in the policy rules) by equations (B19)-(B23), (B3), identities for $y_{t}, \pi_{t}^{d}$, and $i_{t}$, and the 
change in the interest rate, $\Delta i_{t}$.

To set up the system, define an $\left(n_{1} \times 1\right)$ vector $\left(n_{1}=21\right)$ of backward-looking (predetermined) state variables as

$$
\begin{aligned}
x_{1 t} \equiv & \left\{\varepsilon_{t}^{y}, \varepsilon_{t}^{\pi}, u_{t}^{s}, u_{t}^{q}, y_{t}, \pi_{t}^{d}, \pi_{t-1}^{d}, \pi_{t-2}^{d}, \pi_{t-3}^{d}, \pi_{t-1}^{M}, \pi_{t-2}^{M}, \pi_{t-3}^{M},\right. \\
& \left.y_{t}^{f}, \pi_{t}^{f}, \pi_{t-1}^{f}, \pi_{t-2}^{f}, i_{t}^{f}, q_{t}^{A}, \hat{q}_{t-1}, q_{t-1}, i_{t-1}\right\}^{\prime}
\end{aligned}
$$

an $\left(n_{2} \times 1\right)$ vector $\left(n_{2}=3\right)$ of forward-looking state variables as

$$
x_{2 t} \equiv\left\{y_{t+1 \mid t}, \pi_{t+1 \mid t}^{d}, q_{t}\right\}^{\prime},
$$

an $\left(n_{1} \times 1\right)$ vector of disturbances to the predetermined variables as

$$
\begin{aligned}
\varepsilon_{1 t} \equiv & \left\{\varepsilon_{t}^{y}, \varepsilon_{t}^{\pi}, \varepsilon_{t}^{s}, \varepsilon_{t}^{q}, \varepsilon_{t}^{y}, \varepsilon_{t}^{\pi}, \mathbf{0}_{1 \times 6}^{\prime}, \varepsilon_{t}^{y f}, \varepsilon_{t}^{\pi f}, \mathbf{0}_{1 \times 2}^{\prime},\right. \\
& \left.g_{y f} \varepsilon_{t}^{y f}+g_{\pi f} \varepsilon_{t}^{\pi f}, \varepsilon_{t}^{\pi f}-\varepsilon_{t}^{\pi}, \mathbf{0}_{3 \times 1}^{\prime}\right\}^{\prime},
\end{aligned}
$$

and an $\left(n_{z} \times 1\right)$ vector $\left(n_{z}=10\right)$ of goal variables as

$$
z_{t} \equiv\left\{y_{t}, \pi_{t}^{d}, \bar{\pi}_{t}^{d}, \pi_{t}, \bar{\pi}_{t}, \Delta s_{t}, \hat{q}_{t}, \Delta \hat{q}_{t}, i_{t}, \Delta i_{t}\right\}^{\prime}
$$

Then the model can be written on state-space form as

$$
A_{0}\left[\begin{array}{c}
x_{1 t+1} \\
\mathrm{E}_{t} x_{2 t+1}
\end{array}\right]=A_{1} x_{t}+B_{1} i_{t}+\varepsilon_{t+1},
$$

or

$$
\left[\begin{array}{c}
x_{1 t+1} \\
\mathrm{E}_{t} x_{2 t+1}
\end{array}\right]=A x_{t}+B i_{t}+\varepsilon_{t+1},
$$

where

$$
x_{t} \equiv\left[\begin{array}{c}
x_{1 t} \\
x_{2 t}
\end{array}\right], \quad \varepsilon_{t+1} \equiv\left[\begin{array}{c}
\varepsilon_{1 t+1} \\
\mathbf{0}_{n_{2} \times 1}
\end{array}\right],
$$

and $A \equiv A_{0}^{-1} A_{1}, B \equiv A_{0}^{-1} B_{1} \cdot{ }^{29}$

Defining $\iota_{j}$ as a row vector of suitable length with 1 in the $j$ th position and zero elsewhere, the matrices $A_{0}, A_{1}, B_{1}$ are given by

$$
A_{0}=\left[\begin{array}{cccc}
I_{n_{1}} & \multicolumn{3}{c}{\mathbf{0}_{n_{1} \times n_{2}}} \\
& \beta_{y} \varphi_{y} & 0 & 0 \\
\mathbf{0}_{n_{2} \times n_{1}} & 0 & \varphi_{\pi} & \gamma_{q} \\
& 0 & 0 & \vartheta
\end{array}\right],
$$

\footnotetext{
${ }^{29}$ Note that $A_{0}^{-1} \varepsilon_{t}=\varepsilon_{t}$, since $A_{0}$ is block diagonal with an identity matrix as the block $\left(1: n_{1}, 1: n_{1}\right)$ and elements $\left(n_{1}+1: n\right)$ of $\varepsilon_{t}$ are all zero.
} 


$$
\begin{aligned}
A_{1}= & \left\{\mathbf{0}_{2 \times n}^{\prime}, \rho_{s} \iota_{3}^{\prime}, \rho_{q} \iota_{4}^{\prime}, \iota_{22}^{\prime}, \iota_{23}^{\prime}, \iota_{6}^{\prime}, \iota_{7}^{\prime}, \iota_{8}^{\prime}, A_{1,10}^{\prime}, \iota_{10}^{\prime}, \iota_{11}^{\prime}, \rho_{y f} \iota_{13}^{\prime}, \rho_{\pi f} \iota_{14}^{\prime},\right. \\
& \left.\iota_{14}^{\prime}, \iota_{15}^{\prime}, A_{1,17}^{\prime}, A_{1,18}^{\prime}, \iota_{4}^{\prime}+\iota_{24}^{\prime}, \iota_{24}^{\prime}, \mathbf{0}_{1 \times n}^{\prime}, A_{1,22}^{\prime}, A_{1,23}^{\prime}, A_{1,24}^{\prime}\right\}^{\prime},
\end{aligned}
$$

where

$$
\begin{aligned}
& A_{1,10}=\kappa\left(\iota_{6}-\iota_{20}+\iota_{24}\right)+(1-\kappa) \iota_{10}, \\
& A_{1,17}=g_{y f} \rho_{y f} \iota_{13}+g_{\pi f}\left[\left(1+\rho_{\pi f}\right) \iota_{14}+\iota_{15}+\iota_{16}\right], \\
& A_{1,18}=\rho_{\pi f} \iota_{14}+\xi \iota_{18}-\iota_{23}+(1-\xi) \iota_{24} \\
& A_{1,22}=-\beta_{y}\left(1-\varphi_{y}\right) \iota_{5}-\beta_{y f} \iota_{13}+\iota_{22}-4 \beta_{r} \iota_{23}-\beta_{q} \iota_{24}, \\
& A_{1,23}=-\left(1-\varphi_{\pi}\right) \iota_{6}-\gamma_{y} \iota_{22}+\iota_{23}, \\
& A_{1,24}=-\iota_{3}+\vartheta \rho_{\pi f} \iota_{14}-\frac{1}{4} \iota_{17}-(1-\vartheta) \xi \iota_{18}-\vartheta \iota_{23}+\Omega_{q} \iota_{24},
\end{aligned}
$$

and

$$
B_{1}=\left\{\mathbf{0}_{20 \times 1}^{\prime}, 1, \beta_{r}, 0,1 / 4\right\}^{\prime} .
$$

Likewise, the goal variables can be written as

$$
z_{t}=C_{x} x_{t}+C_{i} i_{t}
$$

where

$$
\begin{aligned}
C_{x}= & \left\{\iota_{5}^{\prime}, \iota_{6}^{\prime},\left(\iota_{6}^{\prime}+\iota_{7}^{\prime}+\iota_{8}^{\prime}+\iota_{9}^{\prime}\right), C_{x, 4}^{\prime}, C_{x, 5}^{\prime}, C_{x, 6}^{\prime},\right. \\
& \left.\iota_{4}^{\prime}+\iota_{24}^{\prime}, \iota_{4}^{\prime}+\iota_{24}^{\prime}-\iota_{19}^{\prime}, \mathbf{0}_{1 \times n}^{\prime},-\iota_{21}^{\prime}\right\}^{\prime}, \\
C_{i}= & \left\{\mathbf{0}_{8 \times 1}^{\prime}, 1,1\right\}^{\prime},
\end{aligned}
$$

where

$$
\begin{aligned}
C_{x, 4} & =(1-\eta+\eta \kappa) \iota_{6}+\eta(1-\kappa) \iota_{10}+\eta \kappa\left(\iota_{24}-\iota_{20}\right), \\
C_{x, 5} & =(1-\eta+\eta \kappa) \iota_{6}+(1-\eta)\left[\iota_{7}+\iota_{8}+\iota_{9}\right] \\
& +\eta\left[(2-\kappa) \iota_{10}+\iota_{11}+\iota_{12}\right]+\eta \kappa\left(\iota_{24}-\iota_{20}\right), \\
C_{x, 6} & =\iota_{6}-\iota_{14}-\iota_{20}+\iota_{24} .
\end{aligned}
$$

The covariance matrix of the disturbance vector $\varepsilon_{1 t}$ is given by

$$
\begin{aligned}
\Sigma_{\varepsilon 1}= & \left\{\sigma_{y}^{2}\left[\iota_{1}+\iota_{5}\right]^{\prime}, \sigma_{\pi}^{2}\left[\iota_{2}+\iota_{6}-\iota_{18}\right]^{\prime}, \sigma_{s}^{2} \iota_{3}^{\prime}, \sigma_{q}^{2} \iota_{4}^{\prime}, \sigma_{y}^{2}\left[\iota_{1}+\iota_{5}\right]^{\prime},\right. \\
& \sigma_{\pi}^{2}\left[\iota_{2}+\iota_{6}-\iota_{18}\right]^{\prime}, \mathbf{0}_{6 \times n 1}^{\prime}, \sigma_{y f}^{2}\left[\iota_{13}+g_{y f} \iota_{17}\right]^{\prime}, \\
& \left.\sigma_{\pi f}^{2}\left[\iota_{14}+g_{\pi f} \iota_{17}+\iota_{18}\right]^{\prime}, \mathbf{0}_{2 \times n 1}^{\prime}, \Sigma_{\varepsilon 1,17}^{\prime}, \Sigma_{\varepsilon 1,18}^{\prime}, \mathbf{0}_{3 \times n 1}^{\prime}\right\}^{\prime},
\end{aligned}
$$


where

$$
\begin{aligned}
& \Sigma_{\varepsilon 1,17}=g_{y f} \sigma_{y f}^{2} \iota_{13}+g_{\pi f} \sigma_{\pi f}^{2}\left[\iota_{14}+\iota_{18}\right]+\left(g_{y f}^{2} \sigma_{y f}^{2}+g_{\pi f}^{2} \sigma_{\pi f}^{2}\right) \iota_{17}, \\
& \Sigma_{\varepsilon 1,18}=\sigma_{\pi f}^{2}\left[\iota_{14}+g_{\pi f} \iota_{17}+\iota_{18}\right]+\sigma_{\pi}^{2}\left[\iota_{18}-\iota_{2}-\iota_{6}\right] .
\end{aligned}
$$

\section{B.2 Solving the model}

The central bank is assumed to minimize the intertemporal loss function

$$
J_{0}=\sum_{\tau=0}^{\infty} \delta^{\tau} L_{t+\tau}
$$

where the period loss function is given by

$$
\begin{aligned}
L_{t} & =\bar{\pi}_{t}^{2}+\lambda y_{t}^{2}+\nu\left(i_{t}-i_{t-1}\right)^{2} \\
& =z_{t}^{\prime} K z_{t},
\end{aligned}
$$

where $K$ is a matrix of preference parameters with diagonal $\{\lambda, 0,0,0,1,0,0,0,0, \nu\}$. Using (B40), the period loss function can be written on the standard form as

$$
\begin{aligned}
L_{t} & =z_{t}^{\prime} K z_{t} \\
& =\left[\begin{array}{ll}
x_{t}^{\prime} & i_{t}^{\prime}
\end{array}\right]\left[\begin{array}{c}
C_{x}^{\prime} \\
C_{i}^{\prime}
\end{array}\right] K\left[\begin{array}{ll}
C_{x} & C_{i}
\end{array}\right]\left[\begin{array}{c}
x_{t} \\
i_{t}
\end{array}\right] \\
& =x_{t}^{\prime} C_{x}^{\prime} K C_{x} x_{t}+x_{t}^{\prime} C_{x}^{\prime} K C_{i} i_{t}+i_{t}^{\prime} C_{i}^{\prime} K C_{x} x_{t}+i_{t}^{\prime} C_{i}^{\prime} K C_{i} i_{t} \\
& \equiv x_{t}^{\prime} Q x_{t}+x_{t}^{\prime} U i_{t}+i_{t}^{\prime} U^{\prime} x_{t}+i_{t}^{\prime} R i_{t},
\end{aligned}
$$

where

$$
\begin{aligned}
Q & \equiv C_{x}^{\prime} K C_{x} \\
U & \equiv C_{x}^{\prime} K C_{i} \\
R & \equiv C_{i}^{\prime} K C_{i} .
\end{aligned}
$$

In the benchmark case when the central bank minimizes (B49) under commitment, it can be shown that the solution is given by ${ }^{30}$

$$
k_{1 t+1} \equiv\left[\begin{array}{c}
x_{1 t+1} \\
\zeta_{2 t+1}
\end{array}\right]=M_{c} k_{1 t}+\left[\begin{array}{c}
\varepsilon_{1 t+1} \\
\mathbf{0}_{n 2 \times 1}
\end{array}\right],
$$

\footnotetext{
${ }^{30}$ Söderlind (1999) shows how to calculate optimal policy rules and the associated dynamics in forward-looking rational expectations models. Throughout, the numerical solutions are calculated using Söderlind's Gauss routines.
} 


$$
k_{2 t} \equiv\left[\begin{array}{c}
x_{2 t} \\
i_{t} \\
\zeta_{1 t}
\end{array}\right]=N_{c} k_{1 t}
$$

where $\zeta_{j t}$ is the vector of Lagrange multipliers associated with $x_{j t}$.

An arbitrary simple rule is given by

$$
i_{t}=F_{j} x_{t}
$$

for $j=T, \Delta S, Q, \Delta Q$. To construct such a rule, first express it in terms of the goal variables as

$$
i_{t}=F_{j}^{z} z_{t}
$$

where

$$
F_{j}^{z}=\left\{f_{y}^{j}, \mathbf{0}_{1 \times 3}, f_{\pi}^{j}, f_{\Delta s}^{j}, f_{q}^{j}, f_{\Delta q}^{j}, \mathbf{0}_{1 \times 2}\right\} .
$$

Since $F_{j}^{z} C_{i}=0$ for all $j, F_{j}^{z} z_{t}=F_{j}^{z} C_{x} x_{t}$, and thus

$$
F_{j}=F_{j}^{z} C_{x}
$$

Given this rule, the dynamics of the system is

$$
\begin{aligned}
x_{1 t+1} & =M_{j} x_{1 t}+\varepsilon_{1 t+1} \\
x_{2 t} & =N_{j} x_{1 t},
\end{aligned}
$$

and the value of the loss function is

$$
J_{0}=x_{10}^{\prime} V x_{10}+\frac{\delta}{1-\delta} \operatorname{tr}\left(V \Sigma_{\varepsilon 1}\right),
$$

where $\Sigma_{\varepsilon 1}$ is the covariance matrix of $\varepsilon_{1 t+1}$ and where $V_{s}$ is determined by

$$
V_{s}=P^{\prime}\left[\begin{array}{cc}
Q & U \\
U^{\prime} & R
\end{array}\right] P+\delta M_{j} V_{s+1} M_{j},
$$

where

$$
P=\left[\begin{array}{c}
I_{n 1} \\
N_{j} \\
F_{j}\left[\begin{array}{c}
I_{n 1} \\
N_{j}
\end{array}\right]
\end{array}\right] .
$$

Thus, an optimized simple rule can be found by minimizing $J_{0}$ in equation (B63), which is equivalent to minimizing (B49). 


\section{B.3 Calculating unconditional variances}

In the case of commitment, the covariance matrix of $k_{1 t+1}$ satisfies

$$
\Sigma_{k 1}=M_{c} \Sigma_{k 1} M_{c}^{\prime}+\Sigma_{\varepsilon k 1},
$$

where

$$
\Sigma_{\varepsilon k 1}=\left[\begin{array}{cc}
\Sigma_{\varepsilon 1} & \mathbf{0}_{n 1 \times n 2} \\
\mathbf{0}_{n 2 \times n 1} & \mathbf{0}_{n 2 \times n 2}
\end{array}\right] .
$$

Thus, $\Sigma_{k 1}$ is given by

$$
\operatorname{vec}\left(\Sigma_{k 1}\right)=\left[I_{n^{2}}-M_{c} \otimes M_{c}\right]^{-1} \operatorname{vec}\left(\Sigma_{\varepsilon k 1}\right) .
$$

Since

$$
\begin{aligned}
k_{2 t+1} & =N_{c} k_{1 t+1} \\
& =N_{c}\left(M_{c} k_{1 t}+\varepsilon_{k 1 t+1}\right),
\end{aligned}
$$

stacking $k_{1 t+1}$ and $k_{2 t+1}$, we get

$$
k_{t+1}=H_{c} k_{1 t}
$$

where

$$
k_{t+1}=\left[\begin{array}{l}
k_{1 t+1} \\
k_{2 t+1}
\end{array}\right], \quad H_{c}=\left[\begin{array}{c}
I_{n} \\
N_{c}
\end{array}\right] .
$$

Thus the covariance matrix of $k_{t+1}$ is given by

$$
\Sigma_{k}=H_{c} \Sigma_{k 1} H_{c}^{\prime}
$$

Finally, since the goal variables are given by

$$
\begin{aligned}
z_{t} & =C_{x} x_{t}+C_{i} i_{t} \\
& =\left[\begin{array}{ll}
C_{x} & C_{i}
\end{array}\right]\left[\begin{array}{c}
x_{t} \\
i_{t}
\end{array}\right] \\
& =C_{c}\left[\begin{array}{c}
x_{t} \\
i_{t}
\end{array}\right],
\end{aligned}
$$

its covariance matrix is

$$
\Sigma_{z}=C_{c} \Sigma_{x i} C_{c}^{\prime}
$$


where $\Sigma_{x i}$ is the covariance matrix of the stacked vector $\left\{x_{t}^{\prime}, i_{t}^{\prime}\right\}^{\prime}$, picked out from the matrix $\Sigma_{k}$.

Under a simple rule, the covariance matrix of $x_{1 t}$ is given by

$$
\operatorname{vec}\left(\Sigma_{x 1}\right)=\left[I_{n 1^{2}}-M_{j} \otimes M_{j}\right]^{-1} \operatorname{vec}\left(\Sigma_{\varepsilon 1}\right),
$$

and since the goal variables are given by (partitioning $C_{x}$ and $F_{j}$ conformably with $\left.x_{1 t}, x_{2 t}\right)$

$$
\begin{aligned}
z_{t} & =C_{x} x_{t}+C_{i} i_{t} \\
& =\left[\begin{array}{ll}
C_{x 1} & C_{x 2}
\end{array}\right]\left[\begin{array}{c}
x_{1 t} \\
x_{2 t}
\end{array}\right]+C_{i}\left[\begin{array}{ll}
F_{j 1} & F_{j 2}
\end{array}\right]\left[\begin{array}{c}
x_{1 t} \\
x_{2 t}
\end{array}\right] \\
& =\left[\begin{array}{ll}
C_{x 1} & C_{x 2}
\end{array}\right]\left[\begin{array}{c}
x_{1 t} \\
N_{j} x_{1 t}
\end{array}\right]+C_{i}\left[\begin{array}{ll}
F_{j 1} & F_{j 2}
\end{array}\right]\left[\begin{array}{c}
x_{1 t} \\
N_{j} x_{1 t}
\end{array}\right] \\
& =C_{j} x_{1 t}
\end{aligned}
$$

where $C_{j} \equiv\left[C_{x 1}+C_{i} F_{j 1}+C_{x 2} N_{j}+C_{i} F_{j 2} N_{j}\right]$, its covariance matrix is

$$
\Sigma_{z}=C_{j} \Sigma_{x 1} C_{j}^{\prime}
$$




\section{Additional figures}

Figure C.1: Optimized output and inflation coefficients in different model configurations

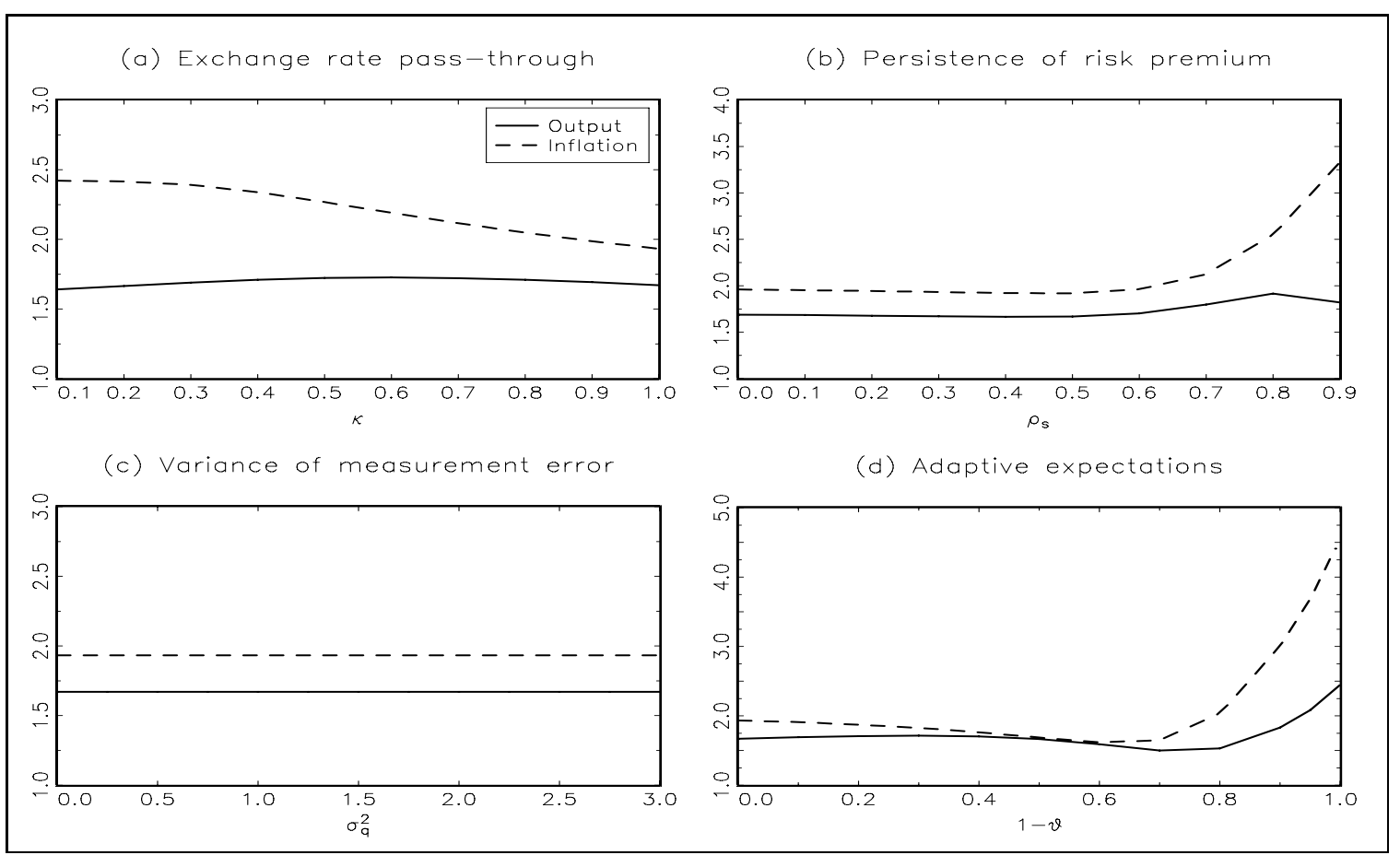

Note: Optimized coefficients on inflation and output. 


\section{References}

Adolfson, Malin, "Optimal monetary policy with incomplete exchange rate passthrough," manuscript, Stockholm School of Economics, September 2000.

Alexius, Annika and Anders Vredin, "Pricing-to-market in Swedish exports," Scandinavian Journal of Economics 101 (2), 223-239, June 1999.

Amato, Jeffery D. and Thomas Laubach, "Rule-of-thumb behavior and monetary policy," manuscript, Bank for International Settlements, April 2000.

Backus, David K. and John Driffill, "The consistency of optimal policy in stochastic rational expectations models," Discussion Paper No. 124, Centre for Economic Policy Research, August 1986.

Ball, Laurence, "Efficient rules for monetary policy," International Finance 2 (1), 63-83, April 1999.

Batini, Nicoletta and Andrew G. Haldane, "Forward-looking rules for monetary policy," in Taylor, John B. (ed.), Monetary Policy Rules, Chicago University Press, 1999.

Batini, Nicoletta, Richard Harrison, and Stephen P. Millard, "Monetary policy rules for an open economy," manuscript, Bank of England, January 2001.

Batini, Nicoletta and Edward Nelson, "Optimal horizons for inflation targeting," Journal of Economic Dynamics and Control 25 (6-7), 891-910, June 2001.

Benigno, Gianluca and Pierpaolo Benigno, "Monetary policy rules and the exchange rate," manuscript, Princeton University, May 2000.

Buiter, Willem H. and Ian Jewitt, "Staggered wage setting with real wage relativities: Variations on a theme of Taylor," Manchester School of Economic and Social Studies 49 (3), 211-228, September 1981.

Cavaglia, Stefano, Willem F. C. Verschoor, and Christian C. P. Wolff, "Further evidence on exchange rate expectations," Journal of International Money and Finance 12 (1), 78-98, February 1993.

Chinn, Menzie and Guy Meredith, "Interest parity at short and long horizons," manuscript, University of California, Santa Cruz, February 2000. Revised version of NBER Working Paper No. 6797.

Corsetti, Giancarlo and Paolo Pesenti, "Optimal interest rate rules and exchange rate pass-through," manuscript, Federal Reserve Bank of New York, December 2000 .

Currie, David and Paul Levine, Rules, Reputation and Macroeconomic Policy Coordination, Cambridge University Press, 1993. 
Dennis, Richard, "Optimal simple targeting rules for small open economies," Working Paper No. 2000-20, Federal Reserve Bank of San Francisco, December 2000.

Estrella, Arturo and Jeffrey C. Fuhrer, "Dynamic inconsistencies: Counterfactual implications of a class of rational expectations models," Working Paper No. 98-5, Federal Reserve Bank of Boston, July 1998. Forthcoming, American Economic Review.

Frankel, Jeffrey A. and Kenneth A. Froot, "Using survey data to test standard propositions regarding exchange rate expectations," American Economic Review 77 (1), 133-153, March 1987.

Froot, Kenneth A. and Jeffrey A. Frankel, "Forward discount bias: Is it an exchange risk premium?" Quarterly Journal of Economics 104 (1), 139-161, February 1989.

Froot, Kenneth A. and Richard H. Thaler, "Anomalies: Foreign exchange," Journal of Economic Perspectives 4 (3), 179-192, Summer 1990.

Fuhrer, Jeffrey C. and George Moore, "Inflation persistence," Quarterly Journal of Economics 110 (1), 127-159, February 1995.

Fuhrer, Jeffrey C., "Habit formation in consumption and its implications for monetary-policy models," American Economic Review 90 (3), 367-390, June 2000.

Ghironi, Fabio, "Alternative monetary rules for a small open economy: The case of Canada," manuscript, Federal Reserve Bank of New York, November 1999.

Goldberg, Pinelopi Koujinaou and Michael M. Knetter, "Goods prices and exchange rates: What have we learned?" Journal of Economic Literature 35 (3), 1243-1272, September 1997.

Hansen, Lars Peter and Thomas J. Sargent, "Robust control and filtering of forwardlooking models," manuscript, Stanford University, October 2000.

Ito, Takatoshi, "Foreign exchange rate expectations: Micro survey data," American Economic Review 80 (3), 434-449, June 1990.

Kennan, John, "The estimation of partial adjustment models with rational expectations," Econometrica 47, 1441-1455, 1979.

Leitemo, Kai and Øistein Røisland, "The choice of monetary policy regime for small open economies," Working Paper No. 5/2000, Norges Bank, July 2000.

Leitemo, Kai, "Open-economy inflation forecast targeting," Working Paper No. 2/2000, Norges Bank, May 2000a.

, "The performance of inflation forecast feedback rules in small open economies," Working Paper No. 11/2000, Norges Bank, October 2000b. 
Liu, Peter C. and G. S. Maddala, "Rationality of survey data and tests for market efficiency in the foreign exchange markets," Journal of International Money and Finance 11 (4), 366-381, August 1992.

MacDonald, Ronald, "Are foreign exchange market forecasters 'rational'? some survey-based tests," Manchester School of Economics and Social Studies 58 (3), 229-241, September 1990.

McCallum, Bennett T. and Edward Nelson, "Nominal income targeting in an openeconomy optimizing model," Journal of Monetary Economics 43 (3), 553-578, June 1999.

McCallum, Bennett T., "Robustness properties of a rule for monetary policy," Carnegie-Rochester Conference Series on Public Policy 29, 173-203, Autumn 1988.

_ "A reconsideration of the uncovered interest parity relationship," Journal of Monetary Economics 33 (1), 105-132, February 1994.

_ - "Issues in the design of monetary policy rules," in Taylor, John B. and Michael Woodford (eds.), Handbook of Macroeconomics, Elsevier, Amsterdam, 1999.

Monacelli, Tommaso, "Open economy policy rules under imperfect pass-through," manuscript, New York University, April 1999.

Naug, Bjørn and Ragnar Nymoen, "Pricing to market in a small open economy," Scandinavian Journal of Economics 98 (3), 329-350, September 1996.

Nessén, Marianne and David Vestin, "Average inflation targeting," Working Paper No. 119, Sveriges Riksbank, December 2000.

Obstfeld, Maurice and Kenneth Rogoff, "New directions for stochastic open economy models," Journal of International Economics 50 (1), 117-153, February 2000.

Orphanides, Athanasios, "Monetary policy evaluation with noisy information," Finance and Economics Discussion Paper No. 1998-50, Board of Governors of the Federal Reserve System, November 1998.

Osterberg, William P., "New results on the rationality of survey measures of exchange-rate expectations," Federal Reserve Bank of Cleveland Economic Review 36 (1), 14-21, Quarter 12000.

Pesaran, M. Hashem, The Limits to Rational Expectations, Blackwell, Oxford, 1987.

Rudebusch, Glenn D. and Lars E. O. Svensson, "Policy rules for inflation targeting," in Taylor, John B. (ed.), Monetary Policy Rules, Chicago University Press, 1999. 
Rudebusch, Glenn D., "Assessing nominal income rules for monetary policy with model and data uncertainty," Working Paper No. 2000-03, Federal Reserve Bank of San Francisco, February 2000a.

, "Is the Fed too timid? Monetary policy in an uncertain world," manuscript, Federal Reserve Bank of San Francisco, June 2000b. Forthcoming, Review of Economics and Statistics.

Sack, Brian, "Does the Fed act gradually? A VAR analysis," Journal of Monetary Economics 46 (1), 229-256, August 2000.

Sargent, Thomas J., "Estimation of dynamic labour demand schedules under rational expectations," Journal of Political Economy 86 (6), 1009-1044, December 1978.

Söderlind, Paul, "Solution and estimation of RE macromodels with optimal policy," European Economic Review 43 (4-6), 813-823, April 1999.

Söderström, Ulf, "Monetary policy with uncertain parameters," Working Paper No. 13, European Central Bank, February 2000a. Forthcoming, Scandinavian Journal of Economics.

_ _ "Should central banks be more aggressive?" manuscript, Sveriges Riksbank, August 2000b.

Svensson, Lars E. O. and Michael Woodford, "Implementing optimal policy through inflation-forecast targeting," manuscript, Institute for International Economic Studies, Stockholm University, November 1999.

_ _ "Indicator variables for optimal policy," Working Paper No. 7953, National Bureau of Economic Research, September 2000.

Svensson, Lars E. O., "Open-economy inflation targeting," Journal of International Economics 50 (1), 155-184, February 2000.

Swanson, Eric T., "On signal extraction and non-certainty equivalence in optimal monetary policy rules," Finance and Economics Discussion Paper No. 2000-32, Board of Governors of the Federal Reserve System, June 2000.

Taylor, John B., "Discretion versus policy rules in practice," Carnegie-Rochester Conference Series on Public Policy 39, 195-214, December 1993.

— - "The robustness and efficiency of monetary policy rules as guidelines for interest rate setting by the European central bank," Journal of Monetary Economics 43 (3), 655-679, June 1999.

, "The role of the exchange rate in monetary policy rules," manuscript, Stanford University, 2000. 
Walsh, Carl E., "Monetary policy trade-offs in the open economy," mimeo, University of California, Santa Cruz, November 1999.

Woodford, Michael, "Optimal monetary policy inertia," Working Paper No. 7261, National Bureau of Economic Research, July 1999. 